\title{
Aloin induced apoptosis by enhancing autophagic flux through the PI3K/AKT axis in osteosarcoma
}

Jiaming He $\mathrm{H}^{1,2,3}$, Wenkan Zhang ${ }^{1,2,3}$, Xiaozhong Zhou ${ }^{1,2,3}$, Weiqi Yan ${ }^{1,2,3^{*}}$ and Zhan Wang ${ }^{1,2,3^{*}}$ (D)

\begin{abstract}
Background: Osteosarcoma is a malignant tumor of bone and soft tissue in adolescents. Due to its tumor biological behavior pattern, osteosarcoma usually generates poor prognosis. Autophagy is an important self-defense mechanism in osteosarcoma.

Methods: Cell viability in $\mathrm{IC}_{50}$ testing and reverse assays was examined by the MTT assay. Cell apoptosis conditions were examined by flow cytometry, Hoechst 33,342 staining and apoptosis-related protein immunoblotting. Autophagy conditions were tested by autophagy-related protein immunoblotting, transmission electron microscopic observation and dual fluorescence autophagy flux detection. The possible targets of aloin were screened out by network pharmacology and bioinformatic methods. Osteosarcoma xenografts in nude BALB/c mice were the model for in vivo research on tumor suppression, autophagy induction, pathway signaling and toxicity tests. In vivo bioluminescence imaging systems, immunohistochemical assays, and gross tumor volume comparisons were applied as the main research methods in vivo.
\end{abstract}

Results: Aloin induced osteosarcoma apoptosis in a dose-dependent manner. Its possible effects on the PI3K/AKT pathway were screened out by network pharmacology methods. Aloin increased autophagic flux in osteosarcoma by downregulating the PI3K/AKT pathway. Aloin promoted autophagic flux in the osteosarcoma cell lines HOS and MG63 in a dose-dependent manner by promoting autophagosome formation. Chloroquine reversed the apoptosispromoting and autophagy-enhancing effects of aloin. Autophagy induced by starvation and rapamycin significantly enhanced the autophagic flux and apoptosis induced by aloin, which verified the role of the PI3K/AKT axis in the pharmacological action of aloin. Therapeutic effects, autophagy enhancement and regulatory effects on the PI3K/ AKT/mTOR pathway were demonstrated in a nude mouse xenogeneic osteosarcoma transplantation model.

Conclusions: Aloin inhibited the proliferation of osteosarcoma by inhibiting the PI3K/AKT/mTOR pathway, increasing autophagic flux and promoting the apoptosis of osteosarcoma cells.

Keywords: Aloin, Network pharmacology, Molecular docking, Autophagy, Osteosarcoma

*Correspondence: wyan@zju.edu.cn; wangzhanhz@zju.edu.cn 1 Department of Orthopedic Surgery, The Second Affiliated Hospital, Zhejiang University School of Medicine, Hangzhou, China

Full list of author information is available at the end of the article

\begin{abstract}
Introduction
Most osteosarcomas originate from primitive mesenchymal cells, which are derived from skeletal tissues [1, 2]. Osteosarcoma mainly harms adolescents and results in poor prognosis, which causes great social harm, and there is also a second smaller peak incidence in the elderly population $[3,4]$.
\end{abstract}

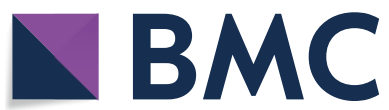

(c) The Author(s) 2021. Open Access This article is licensed under a Creative Commons Attribution 4.0 International License, which permits use, sharing, adaptation, distribution and reproduction in any medium or format, as long as you give appropriate credit to the original author(s) and the source, provide a link to the Creative Commons licence, and indicate if changes were made. The images or other third party material in this article are included in the article's Creative Commons licence, unless indicated otherwise in a credit line to the material. If material is not included in the article's Creative Commons licence and your intended use is not permitted by statutory regulation or exceeds the permitted use, you will need to obtain permission directly from the copyright holder. To view a copy of this licence, visit http://creativecommons.org/licenses/by/4.0/. The Creative Commons Public Domain Dedication waiver (http://creativeco mmons.org/publicdomain/zero/1.0/) applies to the data made available in this article, unless otherwise stated in a credit line to the data. 
The mechanism of autophagy is worth exploring, and various targeted drug studies have highlighted the potential value of autophagy in clinical treatment [5-7]. Exploring important aspects of the autophagy mechanism in osteosarcoma may provide new ideas and insights for the treatment of osteosarcoma. In this study, we mainly focused on autophagy. On the one hand, autophagy is activated as a cytoprotective mechanism, providing nutrition and energy to tumor cells under starvation, thus increasing their resistance to common chemotherapy drugs. Autophagy also plays an important role in osteosarcoma suppression by inducing autophagic cell death $[8,9]$.

The occurrence of autophagy needs to be mediated by PI3KCIII, which is composed of the Vps34 complex [10, 11]. A series of cascade regulations are activated to promote mTOR phosphorylation to inhibit autophagy [10, 11]. mTOR is regulated by the PI3KC III-Vps34-Beclin$1-\mathrm{Vps} 15$ complex to initiate autophagy [10-12]. When nutrients are rich, the PI3K/AKT signaling pathway activates mTOR after sensing glucose and amino acid concentrations to form the mTOR complex [11, 24], which degrades ULK1 and ATG13 through phosphorylation to hinder autophagosome formation [13-17]. When nutrients are deficient, ULK1 combines with ATG13 and RB1CC1 to transform the latter two into phosphorylated forms, competitively reducing ULK1 binding to mtorc1 and promoting autophagosome generation [13-17].

Aloin (National Center for Biotechnology Information (2021). PubChem Compound Summary for CID 12305761, Barbaloin. https://pubchem.ncbi.nlm.nih.gov/ compound/Barbaloin.) is one of the main anthraquinone components extracted from aloe leaf secretion and is a natural C-glycoside of aloe anthrone. Aloin was reported to possess anti-inflammatory, antibacterial, antioxidant, antiviral and anticancer effects [18]. Studies have shown that aloin induces apoptosis in various tumor cells, including breast cancer [19], ovarian cancer [20, 21], B16-F10 mouse melanoma [22] and human Jurkat T lymphocytes [23].

Recent studies have shown that aloin has antitumor effects in various tumors. Its antitumor effects are closely related to cell growth inhibition, cell cycle arrest, and oxidative metabolic regulation.

Aloin induces tumor cell apoptosis through cell cycle arrest. Esmat applied aloin to breast and ovarian tumor cells to arrest the cell cycle in $\mathrm{M}$ phase and induce tumor cell apoptosis $[19,20]$. Aloin reduced the mitotic ratio of cells by inhibiting the expression of topo II $\alpha$ protein and downregulating cyclin B1 expression, thereby inducing the apoptosis of MCF-7 breast cancer cells $[19,20]$.

Nićiforović showed that aloin blocked the cell cycle of HeLaS3 cells in S phase and significantly increased the apoptosis rate [21]. Aloin interacted with CuZnSOD to produce an inhibitory effect, resulting in the accumulation of hydrogen peroxide to produce antiproliferative and cellular toxic effects [21].

Buenz found that after aloin treatment, Jurkat cells decreased in volume, impaired membrane integrity, and lost mitochondrial membrane potential [23]. Aloin induced melanoma cell differentiation by promoting melanin synthesis and transglutaminase activity in B16-F10 melanoma cells [22]. Considering the antitumor potential of aloin, we tried to study the chemotherapy effect of aloin in osteosarcoma, which is a relatively 'tough' tumor.

However, there is no literature report on the effect of aloin on human osteosarcoma and its underlying mechanism. Therefore, we used network pharmacology to study possible drug targets of aloin, which verified the antitumor effect on osteosarcoma in vitro and in vivo. In this study, we mainly discussed the autophagy induced by aloin in osteosarcoma cells and related PI3K/AKT/ mTOR axis changes.

\section{Materials and methods \\ Tumor cell lines}

The selected cell lines were human osteosarcoma cell line MNNG/HOS (CRL-1547 ${ }^{\mathrm{TM}}$, ATCC) and MG-63 (CRL-1427 ${ }^{\mathrm{TM}}$, ATCC). All cell lines were cultured in Dulbecco's modified Eagle's medium (DMEM) with high glucose and L-glutamine (Corning), 10\% fetal bovine serum (Gibco), $100 \mathrm{U} / \mathrm{mL}$ penicillin, and $100 \mu \mathrm{g} / \mathrm{mL}$ streptomycin (Sigma-Aldrich). The cells were incubated at $37^{\circ} \mathrm{C}$ in a moist environment with $5 \% \mathrm{CO}_{2}$, and then harvested and transferred to culture when they reached $70 \%$ to $80 \%$ confluence.

\section{Cell treatment}

PBS, saline, and DMSO (Sigma-Aldrich) were used as vehicle and negative control for all treatments. Aloin (CAS:1415-73-2, 98.32\% purity), Chloroquine (99.5\% purity), Rapamycin (99.94\% purity) (MedChemExpress) was applied for autophagic detection.

\section{MTT assay}

Aloin cytotoxicity against HOS and MG-63 cell-lines was analyzed by MTT assay. HOS and MG-63 cell lines were treated with various concentrations of aloin for 24 , 48 , and $72 \mathrm{~h}$. Triplicate experiments were performed and means \pm SD was represented. The IC50s values of aloin in the HOS and MG-63 cells were calculated by Prism6.

\section{Hoechst 33342 staining detection}

The two cell lines were cultured with different dose of aloin for $24 \mathrm{~h}$, stained and photographed with 
fluorescence microscope under $488 \mathrm{~nm}$. Cell apoptotic morphology was observed and photographed.

\section{Flow cytometry assays}

After $24 \mathrm{~h}$ of aloin administration, HOS and MG63 cells were stained with Annexin V-FITC/PI Cell Apoptosis detection kit. FAC Scan flow cytometer (Beckman, USA) was used to analyze the samples and measure the percentage of apoptotic cells.

\section{Western blot assays}

After $24 \mathrm{~h}$ of aloin, chloroquine, rapamycin and starvation administration, HOS and MG-63 cell lines were lysed in RIPA buffer with protease and phosphatase inhibitor cocktail. Protein samples of same amount were separated by western blot. Blot intensity was analyzed by Image $J$ (v1.51). The primary antibodies applied in this research were as follows: AKT, ATG5, Beclin1, Bcl-2, bcl$\mathrm{xl}$, cleaved caspase 3 , cleaved caspase 7 , cleaved caspase 9, cleaved PARP, mTOR, pho-mTOR (SER2448), phoAKT (SER473), PI3K $\alpha$ (p110), SQSTM1 (P62), LC3B. Beta-actin was used as internal reference. The secondary antibodies were as follows: goat anti-rabbit IgGHRP (1:2000, Biosharp) and goat anti-mouse IgG-HRP (1:2000, Biosharp).

\section{Network pharmacology and bioinformatics analysis on Aloin}

The ligand structural data of aloin was obtained from PubChem (https://pubchem.ncbi.nlm.nih.gov/). Aloin 3D structure model file was loaded into the PharmMapper [42-44] (http://www.lilab-ecust.cn/pharmmapper/) website for reverse screening. The selection standard was as follows: human target protein, duplicate genes merged, fitscore from high to low sorted. Screened results were imported into protein-protein interaction network (protein-protein interaction, PPI) online analysis database STRING (https://string-db.org/) to analyze aloin-related drug targets interaction.

The obtained PPI network results were imported into Cytoscape (v3.6.0) to construct key network of alointarget interactions. The obtained key network targets were uploaded to KEGG (https://www.kegg.jp/) for the construction of signaling pathway network. The threedimensional structure of the target proteins (AKT1, CASP3, SRC, EGFR, MAPK8, MAPK14) for Chimera (v1.13) and Vina (v1.12) flexible matching with aloin were downloaded from the PDB database (http://www.rcsb. org/). The binding scores and $\mathrm{H}$ bonds were calculated.

\section{Autophagy flux detection}

Mycoplasma elimination agent (Plasmocin, InvivoGen), penicillin and streptomycin were administrated for more than two weeks for elimination of microbial contamination before lentiviral transfection. Then the obtained mcherry-EGFP-LC3-puro-HOS and mcherryEGFP-LC3-puro-MG63 cell lines were treated with different concentrations of aloin, chloroquine, rapamycin and starvation for $24 \mathrm{~h}$. The slides were mounted under fluorescence microscope to enumerate the yellow (autophagosome) and red (autolysosome) fluorescent spots.

\section{Turnover experiments}

To validate that Aloin-induced autophagy was modulated by PI3K/AKT/mTOR axis, we co-incubated aloin-treated HOS and MG-63 cells with chloroquine (autophagy inhibitor), starvation (autophagy synergy) and rapamycin (mTOR inhibitor). Cytotoxicity was analyzed by MTT assay. Apoptotic cells cluster was analyzed by flow cytometry. The protein expression levels of autophagic markers and key proteins of PI3K/AKT/mTOR axis were detected by western blot.

\section{Xenograft orthotopic model}

Four-week-old female Balb/c nude mice, which were provided by the Shanghai Laboratory Animal Center of the Chinese Academy of Sciences, were raised under specific pathogen-free conditions. About $5 \times 10^{6}$ stably transfected HOS cells (HOS-luc) for imaging were injected into the right tibia platform under inhalation anesthesia. After 7 days, based on the luminescence intensity measured by in vivo bioluminescence imaging system (IVIS), the remaining mice were randomly divided into three groups (four mice per group). Starting from day 7 , mice in the negative control (NC) group received an intraperitoneal injection of $200 \mu \mathrm{L}$ saline every two days as placebo. Mice in the Aloin group were administered every two days with $40 \mathrm{mg} / \mathrm{kg}$ Aloin in saline $(0.8 \mathrm{mg}$ per mouse in $200 \mu \mathrm{l}$ saline) with $1 \%$ DMSO as hydrotrope, starting one day after tumor inoculation. The cis-platinum group received an intraperitoneal injection of $4 \mathrm{mg} /$ $\mathrm{kg}$ cis-platin (MCE) in saline $(80 \mu \mathrm{g}$ per mouse in $200 \mu \mathrm{l}$ saline) every three days. The sham group received mock operation in the tibia platform and received $200 \mu \mathrm{L}$ saline intraperitoneal injection every 2 days. The luminescence intensity was recorded twice a week. After four weeks of treatment, all mice were euthanized. Tumors, spleens, hearts, livers, lungs, and kidneys were excised and prepared for IHC or HE slide staining.

\section{In vivo bioluminescence assay}

The tumor-bearing mice were anesthetized with isoflurane for about $10 \mathrm{~min}$ after intraperitoneal injection of $150 \mu \mathrm{L}$ of luciferin $(20 \mathrm{mg} / \mathrm{mL})$. In vivo imaging was implemented using an IVIS 200 imaging system and 
analyzed with Living Image Software (Version 3.0.4, Xenogen, Hopkinton, MA, USA).

\section{Histology and immunohistochemistry}

Tumor, cardiac, hepatic, splenic, pulmonary and renal tissue slides were HE stained. Other tumor tissue slides were prepared for IHC. Slides were incubated with primary antibodies (LC3B, mTOR, pho-mTOR, AKT, phoAKT, PI3K $\alpha$ ). The staining intensity was scored by ImageJ (v1.51).

\section{Statistical analysis}

The results were described as the means $\pm \mathrm{SD}$. The data from groups was analyzed by ANOVA test. Pictures were processed by ImageJ (v1.51). Data and figures were managed by Graphpad Prism (v6.0). All statistics were analyzed by IBM SPSS Statistics 20.0 software (IBM, Armonk, NY, USA). Statistical significance was identified as $\mathrm{P}<0.05$. $* * * * * * * * * *$, and $*$ represent $\mathrm{P}<0.0001$, $\mathrm{P}<0.001, \mathrm{P}<0.01$, and $\mathrm{P}<0.05$, respectively.

\section{Results}

Aloin induced HOS and MG-63 cell apoptosis in vitro Cell apoptosis was induced in both the human osteosarcoma cell lines HOS and MG-63 by aloin administration, which showed dose-and time-dependence (Fig. 1). The MTT cell viability assay was conducted to evaluate the inhibition rate curve of the cell lines. The $\mathrm{IC}_{50}$ values of aloin in the HOS cell line were $225.7 \mu \mathrm{M}(24 \mathrm{~h}), 84.94 \mu \mathrm{M}$ $(48 \mathrm{~h})$ and $72.89 \mu \mathrm{M}(72 \mathrm{~h})$. The $\mathrm{IC}_{50}$ values of aloin in the MG-63 cell line were $283.6 \mu \mathrm{M}(24 \mathrm{~h}), 67.99 \mu \mathrm{M}(48 \mathrm{~h})$ and $62.28 \mu \mathrm{M}(72 \mathrm{~h})$ (Fig. 1A). The inhibition rate curve showed inhibition even at low doses, which was different from the feature of low-dose promotion in certain native compounds. With increasing doses, cell viability was significantly inhibited. Therefore, we chose $100 \mu \mathrm{M}$ as the low-dose group and $300 \mu \mathrm{M}$ as the high-dose group for further research.

The average apoptosis rate of the aloin groups (HOS:control 13.24\%, low-dose 32.1\%, high-dose 75.3\%; MG-63:control 10.7\%, low-dose 39.9\%, highdose $78.7 \%$ ) was significantly higher than that of the control group (Fig. 1C). The early and late apoptosis clustering proportions showed obvious differences between HOS and MG-63 cells (Fig. 1C). Although the early apoptosis rate showed no large difference between the cell lines, a significant difference in late apoptosis existed between HOS and MG-63 cells. The apoptosis morphology was studied by Hoechst 33342 staining of slides under fluorescence microscopy observation. The
A
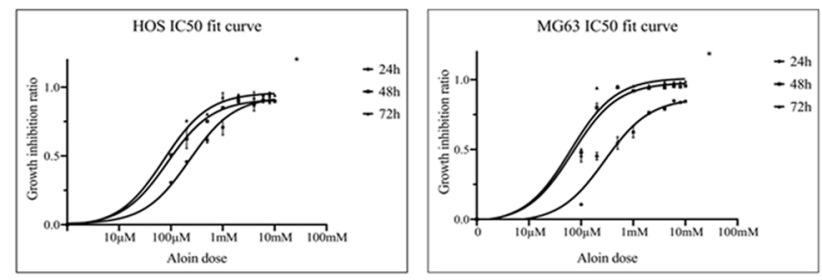

C

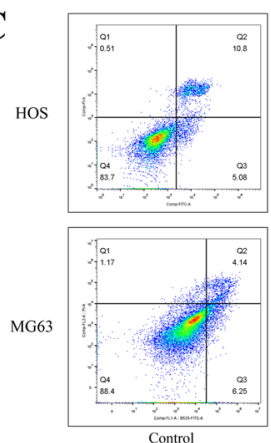

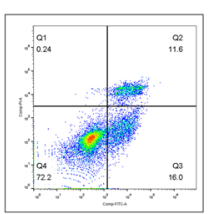

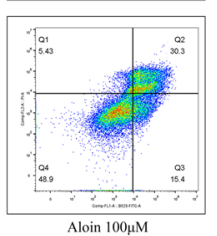

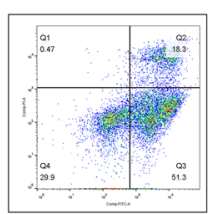

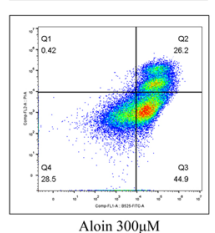

B
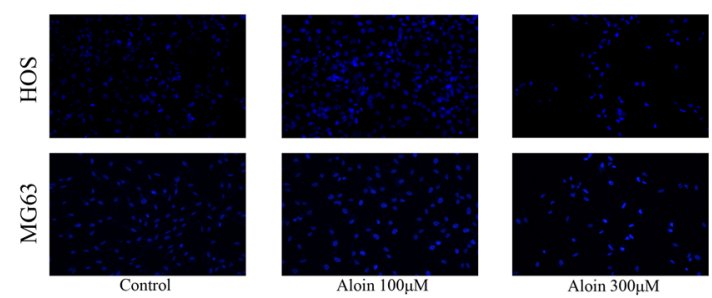

Apoptosis Flowcyto assay

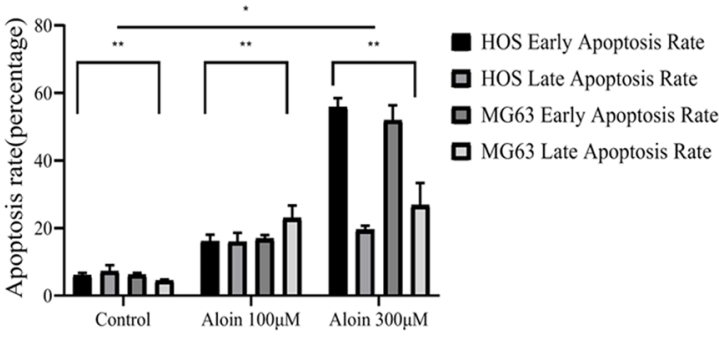

Fig. 1 Aloin inhibited osteosarcoma cell proliferation in vitro. A Human osteosarcoma cell lines (HOS \& MG63) were treated with different concentrations of aloin for 24,48 or $72 \mathrm{~h}$ before MTT assays were performed. B HOS \& MG63 cells were treated with different concentrations of aloin $(0,100$ and $300 \mu \mathrm{M})$ for $24 \mathrm{~h}$ before Hoechst 33,342 staining was utilized for apoptosis morphology analysis. $\mathbf{C}$ HOS \& MG63 cell lines were incubated with aloin for $24 \mathrm{~h}$ before the FITC-annexin V/PI apoptosis detection kit was utilized for flow cytometry. Error bar $=$ mean \pm SD of at least triplicate experiments. ( $\left.{ }^{*} P<0.005,{ }^{* *} P<0.01,{ }^{* *} P<0.001,{ }^{* * * *} P<0.0001\right)$ 
increase in the concentration of aloin reduced the total cell number, and the proportion of densely stained cells increased significantly (Fig. 1B).

Western blotting was used to analyze the expression of apoptosis-related proteins: cleaved PARP, cleaved caspase-3, cleaved caspase-7, cleaved caspase-9, Bcl$\mathrm{xl}$, and Bcl-2. The increasing expression levels of cleaved PARP, cleaved caspase-3, cleaved caspase-7, and cleaved caspase- 9 indicated the initiation of the cell death process (Fig. 2A). The decreased Bcl-2 and $\mathrm{Bcl}-\mathrm{xL}$ in the $\mathrm{BCL}$ family are antiapoptotic proteins (Fig. 2A). The apoptotic protease family is the junction of autophagy and cell death, which may play an important role in cell apoptosis through different pathways. We have reason to infer that the mechanism by which aloin promotes the apoptosis of osteosarcoma cells may involve the cross link between programmed death of tumor cells and autophagy.

\section{Network pharmacology and bioinformatics analysis} on aloin

The annotated candidate genes were ranked in descending order with Fitscore scores by PharmMapper, and 196 candidates were selected for the next step of network construction. A total of 196 annotated aloin targets were imported into the STRING database to construct a protein interaction network (Additional file 1: Datasets). The STRING network analysis showed that 192 nodes interact with each other, 1317 edges can be obtained in the network, and 4 isolated nodes indicate that the target is not involved in interaction (Fig. 3A). In the PPI network structure diagram, AKT and EGFR in the core area had densely interacting lines.

The average degree was 13.7, and the average betweenness was 0.0076 . There were 96 target genes whose midpoint degree centrality exceeded the median (median 9.5) in 196 nodes (Table 1). Among them, AKT,

\section{$\mathbf{A}$}

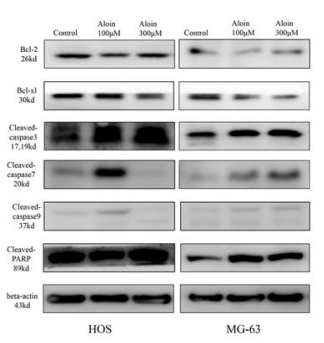

B

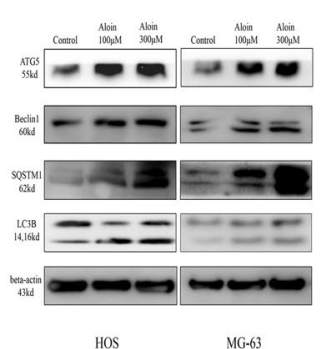

C

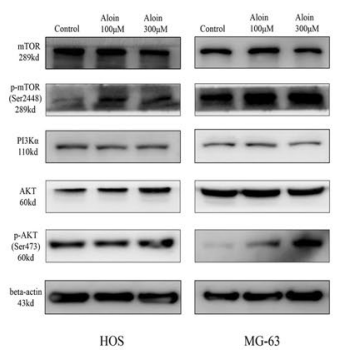

Apoptosis related marker expression levels in HOS

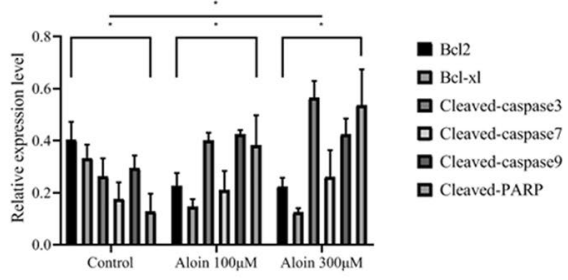

Autophagy related marker expression levels in HOS

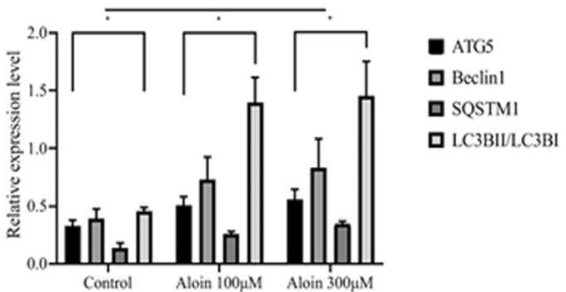

Related pathway expression changes in HOS

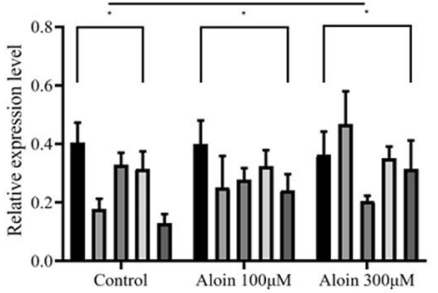

Apoptosis related marker expression levels in MG63

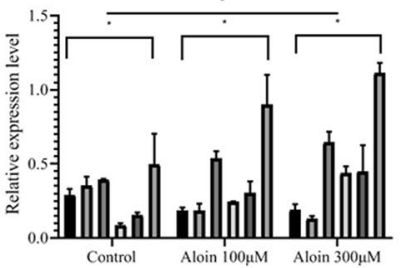

Bcl2

ㅁ Bcl-xl

口 Cleaved-caspase3

口 Cleaved-caspase7

口 Cleaved-caspase9

口 Cleaved-PARP

Autophagy related marker expression levels in MG63

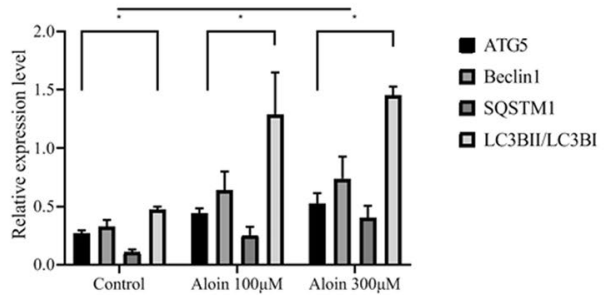

Related pathway expression changes in MG63

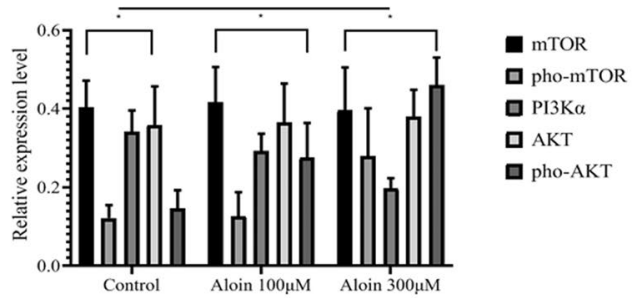

Fig. 2 Aloin induced protein expression level changes in HOS and MG63 cell lines in vitro. The expression levels of apoptosis-related markers (A), autophagy-related markers (B) and PI3K/AKT/mTOR axis proteins $(\mathbf{C})$ were determined by western blot after aloin administration $(0,100$, and $300 \mu \mathrm{M}$ ) for $24 \mathrm{~h}$. Western blot quantitative analysis was performed using ImageJ (ver 1.8). Error bar $=$ mean \pm SD of at least triplicate experiments. $\left({ }^{*} \mathrm{P}<0.005,{ }^{* *} \mathrm{P}<0.01,{ }^{* * *} \mathrm{P}<0.001,{ }^{* * * * P}<0.0001\right)$ 


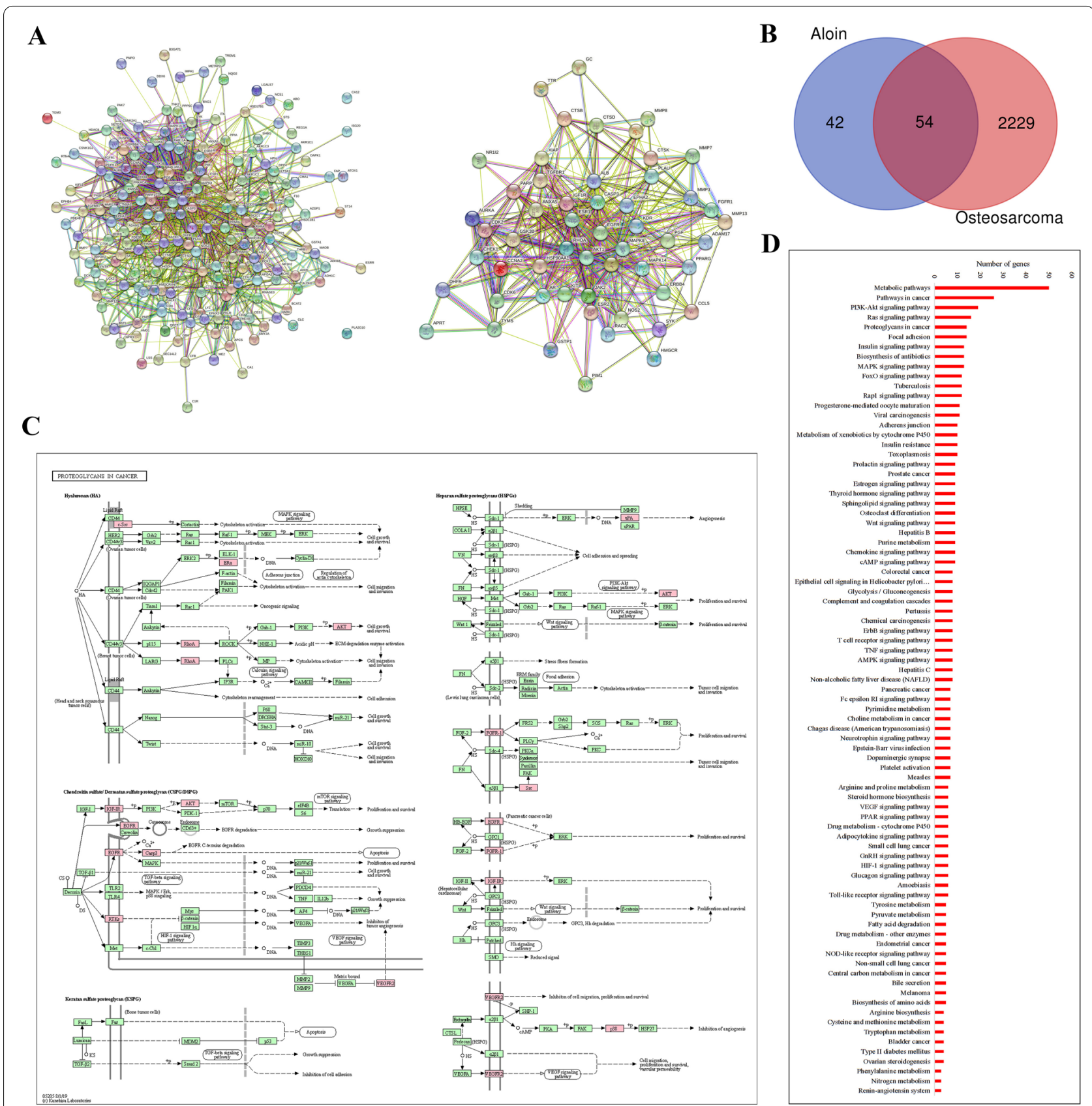

Fig. 3 Network pharmacology and bioinformatics analysis on aloin. A Aloin-targeted proteins screened by PharmMapper were imported into STRING to analyze the interaction network and to construct a key network of aloin drug-target interactions. B The aloin target group and the osteosarcoma-related gene group were annotated to find the intersection of the groups. C Related pathways were screened from a key network of aloin by KEGG pathway analysis. D Aloin-related diseases, signaling pathways and biological processes were screened by the KEGG database. Visualization was performed by Cytoscape (ver 3.6.0), KEGG pathway and STRING databases

EGFR, CASP3, HSP90AA1, MAPK8, ESR1, MAPK14, JAK2, and PARP1 were found, suggesting that these proteins may be important targets for aloin to exert its pharmacological effects.
The word 'Osteosarcoma' was searched in the Disgenet database (www.disgenet.org), disease number C0029463, and the screening condition was 'Summary of GDAs', with 2283 pieces of gene information obtained. The 
Table 1 Selcect Aloin targets and network topology parameter

\begin{tabular}{|c|c|c|c|}
\hline Gene & Degree & Betweenness & Closeness \\
\hline ALB & 94 & 0.22467212 & 0.64726027 \\
\hline AKT1 & 82 & 0.10659732 & 0.61967213 \\
\hline EGFR & 65 & 0.05548461 & 0.57446809 \\
\hline SRC & 59 & 0.04756542 & 0.55752212 \\
\hline CASP3 & 57 & 0.04143446 & 0.5625 \\
\hline HSP90AA1 & 57 & 0.05023598 & 0.55588235 \\
\hline MAPK8 & 52 & 0.02459074 & 0.53846154 \\
\hline ESR1 & 52 & 0.03272838 & 0.53846154 \\
\hline $\mathrm{RHOA}$ & 42 & 0.02871204 & 0.51780822 \\
\hline MAPK14 & 39 & 0.02442919 & 0.50670241 \\
\hline NOS3 & 38 & 0.02906078 & 0.52793296 \\
\hline ANXA5 & 36 & 0.00644395 & 0.50534759 \\
\hline$A R$ & 36 & 0.01980948 & 0.504 \\
\hline KDR & 31 & 0.00735314 & 0.49606299 \\
\hline IGF1R & 28 & 0.00777869 & 0.4871134 \\
\hline PGR & 28 & 0.00682124 & 0.48586118 \\
\hline JAK2 & 26 & 0.00395944 & 0.48337596 \\
\hline XIAP & 26 & 0.00384509 & 0.47848101 \\
\hline DHFR & 26 & 0.03720463 & 0.48963731 \\
\hline SERPINA1 & 26 & 0.02045756 & 0.48461538 \\
\hline F2 & 25 & 0.0220183 & 0.47487437 \\
\hline NOS2 & 25 & 0.02107948 & 0.48963731 \\
\hline LCK & 24 & 0.00374638 & 0.47848101 \\
\hline PRKACA & 24 & 0.01605781 & 0.45215311 \\
\hline PARP1 & 24 & 0.00296672 & 0.47607053 \\
\hline HSPA8 & 24 & 0.00657807 & 0.48461538 \\
\hline SOD2 & 24 & 0.01434656 & 0.48461538 \\
\hline PTPN1 & 23 & 0.00625243 & 0.47848101 \\
\hline TYMS & 23 & 0.02290566 & 0.46210269 \\
\hline CCL5 & 23 & 0.02444585 & 0.46782178 \\
\hline AKR1B1 & 23 & 0.01604294 & 0.4871134 \\
\hline REN & 23 & 0.01096858 & 0.48091603 \\
\hline CTSD & 23 & 0.01401781 & 0.4871134 \\
\hline CTSB & 22 & 0.00521861 & 0.4713217 \\
\hline PPARG & 22 & 0.01297883 & 0.47848101 \\
\hline GSK3B & 22 & 0.0135452 & 0.47607053 \\
\hline MMP3 & 22 & 0.00435397 & 0.46898263 \\
\hline CDK2 & 22 & 0.00497381 & 0.47969543 \\
\hline CCNA2 & 21 & 0.00303664 & 0.47487437 \\
\hline ESR2 & 20 & 0.00923214 & 0.47368421 \\
\hline NQO1 & 20 & 0.01513652 & 0.48337596 \\
\hline LDHB & 20 & 0.02011272 & 0.41906874 \\
\hline PLAU & 20 & 0.01704925 & 0.46666667 \\
\hline APRT & 20 & 0.01825685 & 0.41906874 \\
\hline HK1 & 20 & 0.01457167 & 0.47969543 \\
\hline CDK6 & 19 & 0.00306573 & 0.4375 \\
\hline GSR & 19 & 0.00645307 & 0.48461538 \\
\hline GSTP1 & 19 & 0.018327 & 0.47368421 \\
\hline CHEK1 & 19 & 0.00214974 & 0.44575472 \\
\hline
\end{tabular}

Table 1 (continued)

\begin{tabular}{|c|c|c|c|}
\hline Gene & Degree & Betweenness & Closeness \\
\hline KIT & 18 & 0.01193652 & 0.46323529 \\
\hline ADAM17 & 18 & 0.0033682 & 0.45985401 \\
\hline BACE1 & 17 & 0.00213241 & 0.45873786 \\
\hline MMP13 & 17 & 0.0012115 & 0.45873786 \\
\hline CASP7 & 17 & 7.17E-04 & 0.45985401 \\
\hline AURKA & 17 & 0.00146614 & 0.4375 \\
\hline MMP7 & 17 & $8.03 \mathrm{E}-04$ & 0.45873786 \\
\hline CTSG & 16 & 0.00426012 & 0.43851508 \\
\hline MAPK10 & 16 & 0.01109269 & 0.45762712 \\
\hline TTR & 15 & 0.00498248 & 0.43648961 \\
\hline CTSK & 15 & 0.00240011 & 0.42857143 \\
\hline FGFR1 & 15 & 0.00103615 & 0.45 \\
\hline PGF & 15 & 0.00283624 & 0.45542169 \\
\hline MMP8 & 15 & 0.0060175 & 0.45985401 \\
\hline SELP & 15 & 0.00529684 & 0.45432692 \\
\hline CTNNA1 & 15 & 0.00111691 & 0.41629956 \\
\hline GC & 14 & 0.00248048 & 0.43052392 \\
\hline RXRA & 14 & 0.00553557 & 0.44893112 \\
\hline TGFBR1 & 13 & 0.00140318 & 0.44893112 \\
\hline RAC2 & 13 & 0.00111334 & 0.42281879 \\
\hline PDPK1 & 13 & $4.16 \mathrm{E}-04$ & 0.43150685 \\
\hline FKBP1A & 13 & 0.00421252 & 0.43249428 \\
\hline CDA & 13 & 0.00590545 & 0.37724551 \\
\hline PCK1 & 13 & 0.00718678 & 0.45 \\
\hline RHEB & 12 & 0.00261494 & 0.43052392 \\
\hline PNP & 12 & 0.00616886 & 0.375 \\
\hline SULT2A1 & 12 & 0.00444855 & 0.43953488 \\
\hline LYZ & 12 & 0.00507557 & 0.42954545 \\
\hline AKR1C3 & 12 & 0.00267438 & 0.39130435 \\
\hline EPHA2 & 11 & 0.00216285 & 0.421875 \\
\hline PAH & 11 & 0.00349199 & 0.44158879 \\
\hline $\mathrm{AHCY}$ & 11 & 0.00463874 & 0.40997831 \\
\hline RAB11A & 11 & 0.01089449 & 0.44893112 \\
\hline RAB5A & 11 & $3.99 E-04$ & 0.44158879 \\
\hline PDE5A & 11 & 0.00318536 & 0.44055944 \\
\hline TYMP & 11 & 0.00444257 & 0.42567568 \\
\hline NR1I2 & 11 & 0.00561541 & 0.44680851 \\
\hline F7 & 11 & 0.0018532 & 0.42281879 \\
\hline SYK & 11 & 0.00397399 & 0.43249428 \\
\hline ERBB4 & 11 & $1.90 \mathrm{E}-04$ & 0.42 \\
\hline HMGCR & 11 & 0.00974638 & 0.4478673 \\
\hline HSD17B1 & 10 & 0.00143199 & 0.37649402 \\
\hline OTC & 10 & 0.01325372 & 0.421875 \\
\hline PPIA & 10 & 0.00163724 & 0.45432692 \\
\hline PIM1 & 10 & 0.01355121 & 0.43448276 \\
\hline CSNK2A1 & 10 & 0.00106061 & 0.41814159 \\
\hline SORD & 10 & 0.00381009 & 0.43851508 \\
\hline
\end{tabular}


aloin target group (96 targets) and the osteosarcomarelated gene group (2283 targets) were annotated with the UNIPROT gene coding to find the intersection of both groups. A Venn diagram was generated according to the intersection (Fig. 3B). Fifty-four core targets were screened to form the key network genes (Table 2).

A total of 59 closely related genes were screened in the signaling pathways enriched by KEGG, involving 127 related diseases, signaling pathways and biological processes (Fig. 3D). Among the 127 signaling pathways and biological processes, 24 signaling pathways were directly related to tumors, occupying a high proportion of $18.89 \%$ (24/127). There were 15 PI3K-AKT pathway-related targets and 14 MAPK pathway-related targets. Important nodes such as AKT1, CASP3, JAK2, MAPK8, MAPK14, and EGFR according to the degree of target association were mapped. Enrichment analysis of KEGG mapper and KEGG pathways found that multiple signaling pathways were related to the onset of cancers. AKT1, CASP3, EGFR, SRC, MAPK8, and MAPK14 were considered key proteins in the network (Fig. 3C). The 3D structures of the AKT1, CASP3, SRC, EGFR, MAPK8, and MAPK14 proteins were obtained from the PDB database (https:// www1.rcsb.org/) and imported into Chimera (v1.13) with Vina (v1.12). The candidate targets were preprocessed and forward docked with the aloin molecule (Fig. 4B; Table 3). Molecular graphics and analyses were performed with UCSF Chimera, developed by the Resource for Biocomputing, Visualization, and Informatics at the University of California, San Francisco, with support from NIH P41-GM103311 [45].

Based on the abovementioned network pharmacology research results, the regulatory effect of aloin was likely to be closely related to key pathway proteins such as AKT1, EGFR and CASP3. PI3K-AKT-related pathways were also closely involved in the results. We considered the autophagy process, which is closely related to the $\mathrm{PI} 3 \mathrm{~K} / \mathrm{AKT} / \mathrm{mTOR}$ pathway, to be the keystone to study the antitumor mechanism of aloin.

\section{Aloin upregulated autophagic flux in HOS and MG-63 cells in vitro}

Western blotting was conducted to detect autophagy protein markers, such as ATG5, P62, Beclin-1, and the ratio of LC3BI and LC3BII protein expression in the aloin-administered cultivation system. Aloin significantly increased the ratio of LC3BII/LC3BI in a dosedependent manner (Fig. 2B). Before aloin treatment, the ratio of LC3BII/LC3BI in the control group was less than one, which indicated that the control group did not enter the initial process of autophagy. In the aloin groups, the expression of LC3BII and LC3BI increased compared with that in the control group, and the LC3BII/LC3BI
Table 2 Aloin and osteosarcoma intersection gene list (54 genes)

\begin{tabular}{|c|c|c|}
\hline Gene name & Uniprot ID & Protein name \\
\hline NOS2 & P35228 & Nitric oxide synthase, inducible \\
\hline FGFR1 & P11362 & Fibroblast growth factor receptor 1 \\
\hline GSTP1 & P09211 & Glutathione S-transferase P \\
\hline AURKA & 014965 & Aurora kinase A \\
\hline DHFR & P00374 & Dihydrofolate reductase \\
\hline GC & P02774 & Vitamin D-binding protein \\
\hline CTSB & P07858 & Cathepsin B \\
\hline KIT & P10721 & Mast/stem cell growth factor receptor Kit \\
\hline JAK2 & 060674 & Tyrosine-protein kinase JAK2 \\
\hline XIAP & P98170 & E3 ubiquitin-protein ligase XIAP \\
\hline CTSK & P43235 & Cathepsin K \\
\hline ESR1 & P03372 & Estrogen receptor \\
\hline TYMS & Q53Y97 & Thymidylate synthase \\
\hline CCNA2 & P20248 & Cyclin-A2 \\
\hline HMGCR & P04035 & $\begin{array}{l}\text { 3-hydroxy-3-methylglutaryl-coenzymeA } \\
\text { reductase }\end{array}$ \\
\hline MMP3 & P08254 & Stromelysin-1 \\
\hline MMP8 & P22894 & Neutrophil collagenase \\
\hline PGF & P49763 & Placenta growth factor \\
\hline EGFR & P00533 & Epidermal growth factor receptor \\
\hline MAPK8 & P45983 & Mitogen-activated protein kinase 8 \\
\hline SRC & P12931 & Proto-oncogene tyrosine-protein kinase Src \\
\hline CDK2 & P24941 & Cyclin-dependent kinase 2 \\
\hline CCL5 & P13501 & C-C motif chemokine 5 \\
\hline ADAM17 & P78536 & $\begin{array}{l}\text { Disintegrin and metalloproteinase domain- } \\
\text { containing protein } 17\end{array}$ \\
\hline REN & P00797 & Renin \\
\hline ALB & P02768 & Albumin \\
\hline ESR2 & Q92731 & Estrogen receptor beta \\
\hline APRT & P07741 & Adenine phosphoribosyltransferase \\
\hline ERBB4 & Q15303 & Receptor tyrosine-protein kinase erbB-4 \\
\hline PLAU & P00749 & Urokinase-type plasminogen activator \\
\hline MMP13 & P45452 & Collagenase 3 \\
\hline EPHA2 & P29317 & Ephrin type-A receptor 2 \\
\hline RAC2 & P15153 & Ras-related C 3 botulinum toxin substrate 2 \\
\hline CHEK1 & 014757 & Serine/threonine-protein kinase Chk1 \\
\hline PPARG & P37231 & $\begin{array}{l}\text { Peroxisome proliferator-activated receptor } \\
\text { gamma }\end{array}$ \\
\hline $\mathrm{RHOA}$ & P61586 & Transforming protein RhoA \\
\hline PIM1 & P11309 & Serine/threonine-protein kinase pim-1 \\
\hline MAPK14 & Q16539 & Mitogen-activated protein kinase 14 \\
\hline CDK6 & Q00534 & Cyclin-dependent kinase 6 \\
\hline TGFBR1 & P36897 & TGF-beta receptor type-1 \\
\hline CTSD & P07339 & Cathepsin D \\
\hline ANXA5 & P08758 & Annexin A5 \\
\hline HSP90AA1 & P07900 & Heat shock protein HSP 90-alpha \\
\hline CASP3 & P42574 & Caspase-3 \\
\hline PARP1 & P09874 & Poly [ADP-ribose] polymerase 1 \\
\hline KDR & P35968 & Vascular endothelial growth factor receptor 2 \\
\hline
\end{tabular}


Table 2 (continued)

\begin{tabular}{|c|c|c|}
\hline Gene name & Uniprot ID & Protein name \\
\hline TTR & P02766 & Transthyretin \\
\hline SYK & P43405 & Tyrosine-protein kinase SYK \\
\hline IGF1R & P08069 & Insulin-like growth factor 1 receptor \\
\hline AKT1 & P31749 & RAC-alpha serine/threonine-protein kinase \\
\hline $\mathrm{NR} 112$ & O75469 & $\begin{array}{l}\text { Nuclear receptor subfamily } 1 \text { group I mem- } \\
\text { ber } 2\end{array}$ \\
\hline$A R$ & P10275 & Androgen receptor \\
\hline MMP7 & P09237 & Matrilysin \\
\hline GSK3B & P49841 & Glycogen synthase kinase-3 beta \\
\hline
\end{tabular}

ratio of the groups was found to be greater than one, indicating that after aloin treatment, LC3BI transformed into LC3BII and aloin could increase autophagy. At the same time, we measured the expression levels of the autophagy marker proteins ATG5 and Beclin-1. Both expressions increased with increasing aloin concentration. The above results fully demonstrated that aloin significantly promoted the autophagy production process (Fig. 2B). At the same time, P62/SQSTM1 expression was increased. Increased Sequestosome-1 usually represents autophagy inhibition [30]. In actual research processes, an increase in P62 is commonly observed when autophagy is activated, especially under drug stimulation and oxidative stress [25].

To clarify the specific effect of aloin on autophagy, a combination of multiple research methods was needed to evaluate autophagy flux changes. Autophagosome dynamic formation, autophagosome-lysosome binding, and autophagy substrate degradation were also detected (Fig. 5A).

After treating osteosarcoma cell lines with different concentrations of aloin, both the autophagosomes and autophagolysosomes counted under a fluorescence microscope increased. This phenomenon was in line with the increasing trend of the LC3B protein expression level measured in the western blot experiment. Although the

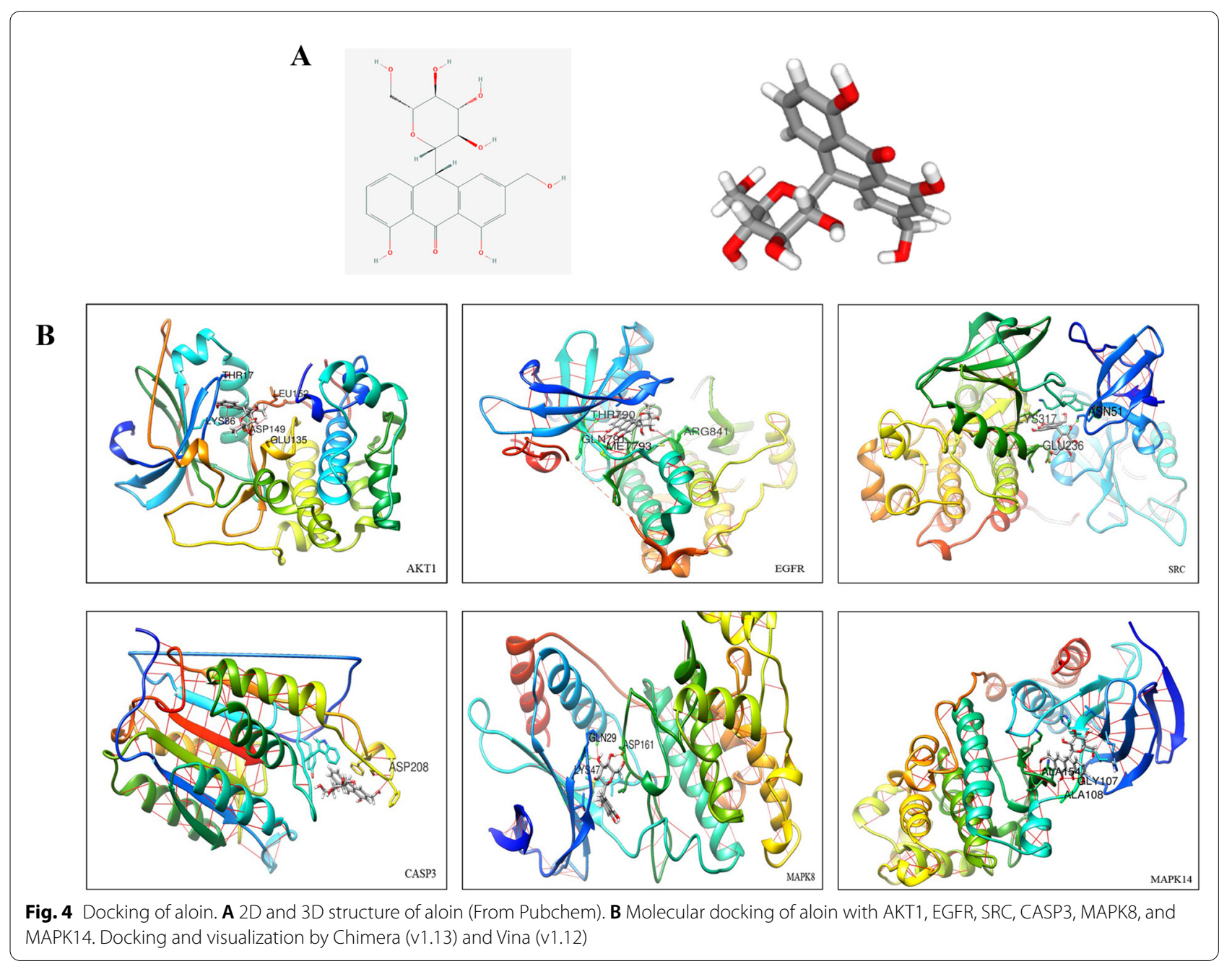


Table 3 Aloin docking with key proteins

\begin{tabular}{|c|c|c|c|}
\hline PDB ID & Score & Target gene & $\mathrm{H}$ bonds \\
\hline 3CQW & -8.0 & AKT1 & 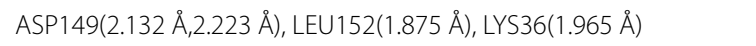 \\
\hline $2 \mathrm{ITX}$ & -8.3 & EGFR & 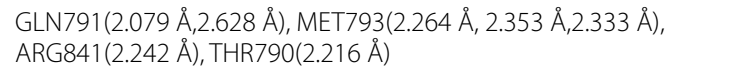 \\
\hline $2 \mathrm{H} 8 \mathrm{H}$ & -8.4 & SRC & 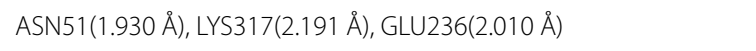 \\
\hline 3DEJ & -7.6 & CASP3 & ASP208(2.574 Å) \\
\hline 1 UKI & -8.0 & MAPK8 & ASP161 (1.854,1.526 ̊̊), CYS47(1.930 ̊̊), GLN29 (2.226 ̊̊) \\
\hline 1W84 & -8.0 & MAPK14 & $\operatorname{GLY} 107(2.274 \AA, 2.108 \AA), \operatorname{ALA108}(2.204 \AA, 2.274 \AA), \operatorname{ALA154}(2.304 \AA)$ \\
\hline
\end{tabular}

expression of P62/SQSTM1 increased, increased degradation did not significantly inhibit the overall autophagic flux. Aloin increased the autophagic flux in a dosedependent manner, which mainly relied on an increase in autophagy (Fig. 5B).

\section{Aloin induced autophagy-related apoptosis in HOS and MG-63 cells via the PI3K/AKT/mTOR axis}

Aloin might increase autophagic flux through the PI3K/ AKT/mTOR pathway in HOS and MG-63 cell lines. Our experiments show that aloin-related $\mathrm{PI} 3 \mathrm{~K} / \mathrm{AKT} / \mathrm{mTOR}$ axis regulation inhibited the growth of tumor cells and induced autophagy. In the previous part of the study, network pharmacology research and gene enrichment studies found that active aloin pharmaceutical targets were closely related to the PI3K/AKT signaling pathway. Therefore, we inferred that aloin may regulate osteosarcoma through this pathway. Western blot analysis was performed to determine the expression levels of mTOR, phosphorylated mTOR, regulatory subunit PI3K $\alpha$, AKT, and phosphorylated AKT. Aloin downregulated the expression of PI3K $\alpha$ in a dose-dependent manner and upregulated the phosphorylation levels of mTOR and $\mathrm{AKT}$ at 100 and $300 \mu \mathrm{M}$ (Fig. 2C).

On this basis, we applied methods to induce autophagy in osteosarcoma cells, inhibit the autophagy process of osteosarcoma cells, and inhibit the phosphorylation level of mTOR by rapamycin to clarify the relationships among aloin, autophagy, the PI3K/AKT/mTOR axis and apoptosis. Apoptosis, autophagy markers and PI3K/AKT/mTOR proteins were tested by western blot assay to observe the expression changes under different conditions. The MTT assay and flow cytometry were carried out to determine growth viability and apoptotic cell clusters of osteosarcoma in all regulatory groups. Dual fluorescence autophagy flux detection analysis of the autophagic flux in the three regulatory groups was performed.

We found that when chloroquine and aloin were both administered to the culture system for $24 \mathrm{~h}$, the growth activity of osteosarcoma cells recovered to a certain extent, and the proportions of apoptotic clusters showed a slight decline (Fig. 6A, B). Western blotting assays indicated that apoptosis and autophagy markers were decreased (Fig. 7A). The expression levels of downregulated PI3K $\alpha$ recovered, and the upregulated phosphorylated levels of mTOR and AKT were reversed (Fig. 8A). Dual fluorescence autophagic flux detection found that chloroquine significantly inhibited the autophagic flux induced by aloin. Using a fluorescence microscope, it was observed that the number of yellow spots decreased, and the number of red spots increased, which reversed the yellow and red spots augmented induced by aloin alone (Fig. 6C).

To further investigate the biological effects of aloin on autophagy, we found that when the cells were starved, starvation had a synergistic antitumor effect. After the dual administration of aloin and starvation for $24 \mathrm{~h}$, the proliferation ability of osteosarcoma cells was obviously inhibited, and the proportion of apoptotic cells obviously increased (Fig. 8A, B). Western blot analysis found that apoptosis marker expression was promoted and autophagy-related proteins were increased. Downregulated PI3K $\alpha$ rose to a certain extent, and phosphorylated levels of mTOR and AKT were further upregulated (Fig. 7B). Dual fluorescence autophagic flux detection found that the synergistic effect of starvation and aloin led to a further augmentation in the autophagic flux. As observed with a fluorescence microscope, the number of yellow and red spots in the dual-administration group increased more significantly than in the starvation or aloin group alone (Fig. 8C).

Aloin significantly upregulated the phosphorylation levels of mTOR and AKT while promoting autophagy, inhibiting tumor cells, and downregulating PI3Ka. To further study the aloin-induced upregulation of phosphorylated mTOR and AKT, rapamycin was applied to inhibit mTOR. When rapamycin was applied as a mTOR inhibitor in this turnover experiment, phosphorylation levels of AKT and mTOR were downregulated by rapamycin, while the inhibition of PI3Ka was not relieved (Fig. 7C). Downregulated phosphorylation levels of AKT and mTOR did not inhibit autophagy. In the rapamycin administration group alone, the mTOR blockade induced by rapamycin returned to PI3K $\alpha$ expression and 
A
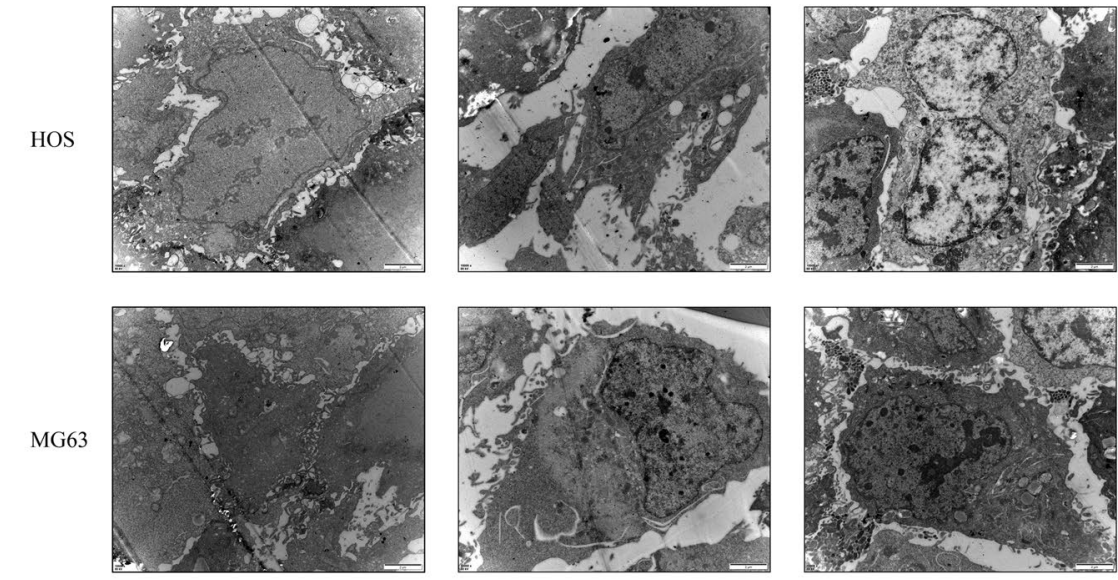

B

Control

Aloin $100 \mu \mathrm{M}$

Aloin $300 \mu \mathrm{M}$
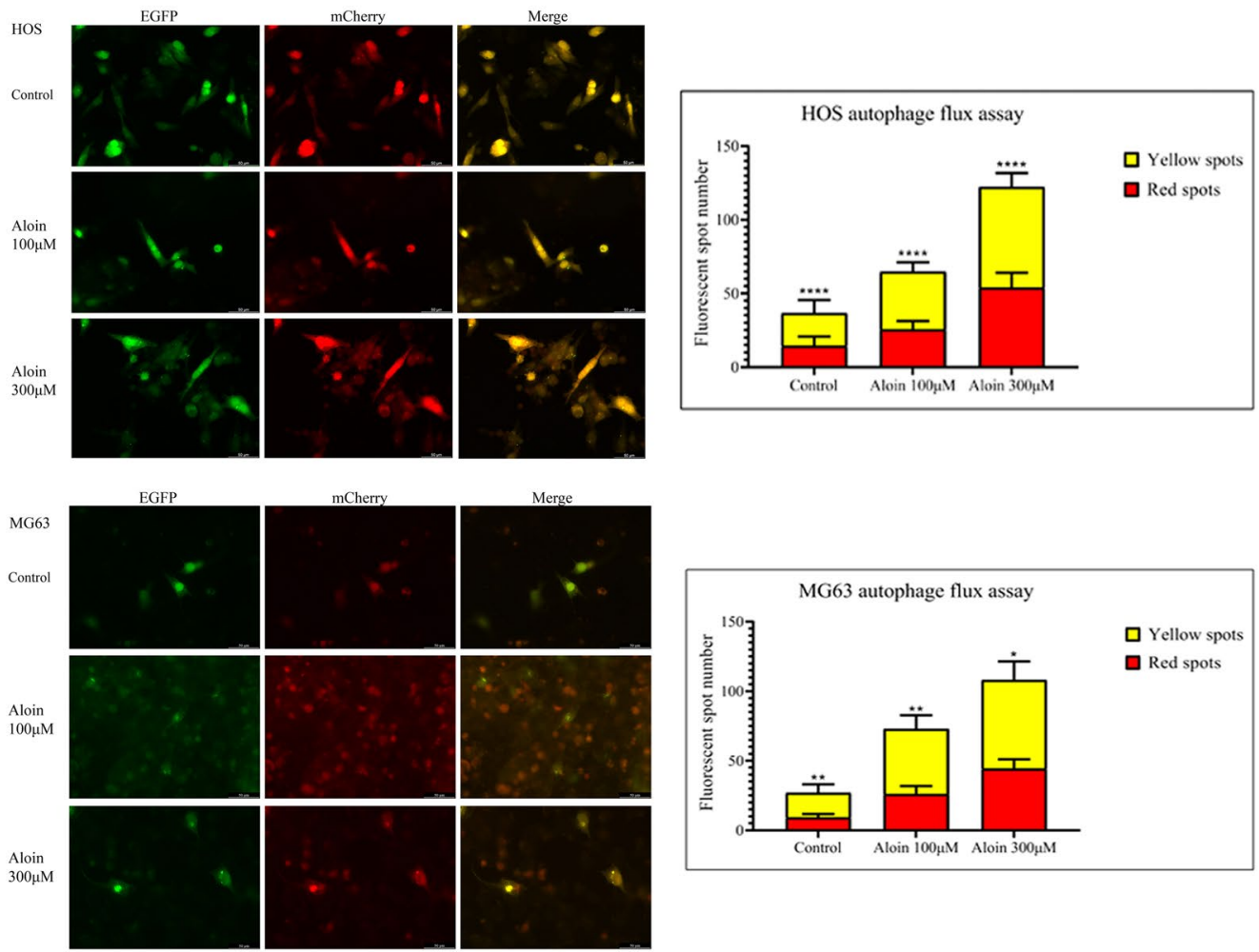

Fig. 5 Autophagy assay in aloin-treated HOS \& MG63 cells. A Transmission electron microscopy scanning of aloin-treated HOS \& MG63 cells to observe autophagosome formation. B Dual-fluorescence autophagy flux assay in aloin-treated HOS \& MG63 cells. The wavelength was $488 \mathrm{~nm}$ and $560 \mathrm{~nm}$. A fluorescence spot count was applied by ImageJ ( $\mathrm{v} 1.8)$. Error bar $=$ mean $\pm S D$ of at least triplicate experiments. $\left({ }^{*} P<0.005,{ }^{* *} P<0.01\right.$, $\left.{ }^{* * *} \mathrm{P}<0.001,{ }^{* * * *} \mathrm{P}<0.0001\right)$

promoted its expression. However, this effect did not reverse the PI3K $\alpha$ inhibition induced by aloin in the dual-administration group. The final biological effect of the combined administration was still the inhibition of cell growth and autophagy induction (Fig. 9). The final inhibition effect was enhanced by the synergy of aloin and rapamycin (Figs. 9A, B). 
A

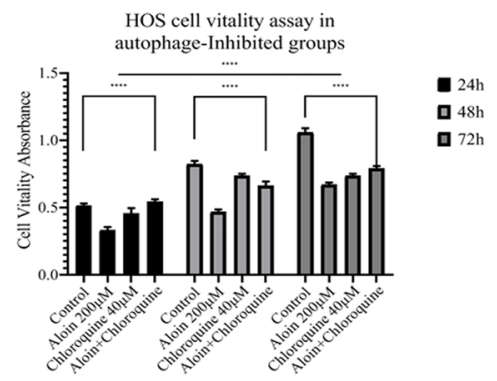

B
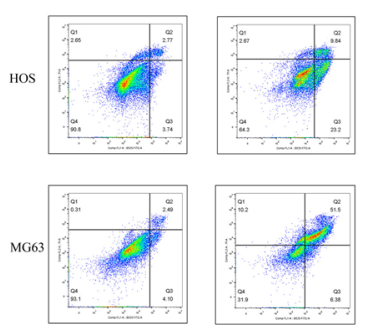

Control

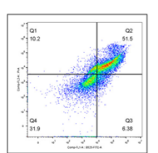

Aloin 200uM
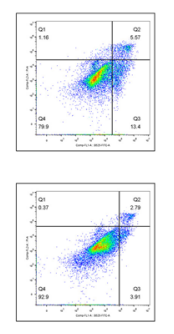

Chloroquine 40uM
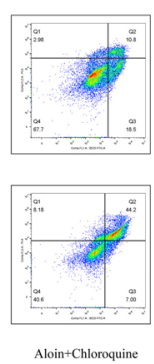

C
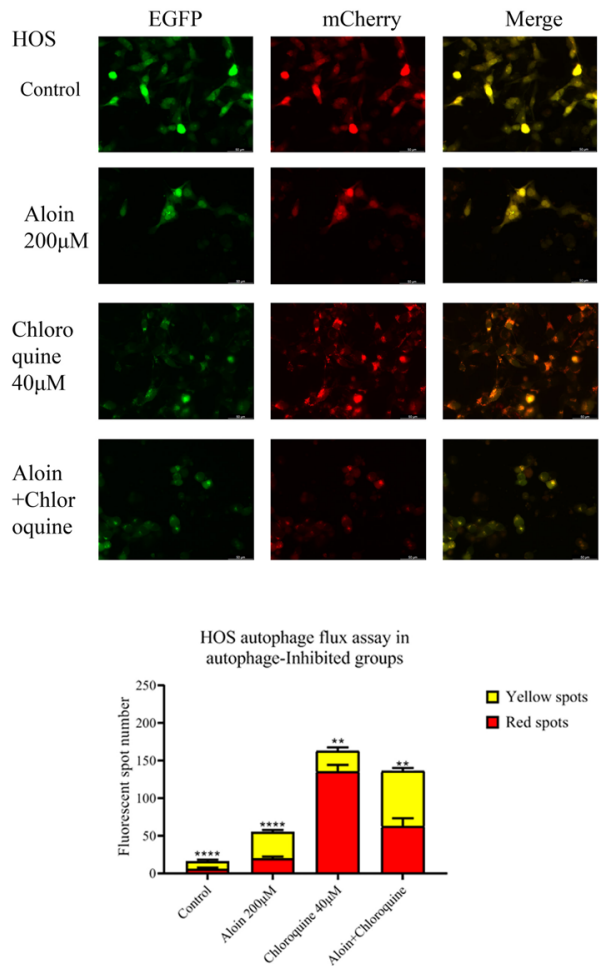

Fig. 6 Aloin and chloroquine coadministration for turnover assays in HOS and MG63 cell lines. A After 24 h of treatment, MTT assays (A), flow cytometry assays (B), and dual fluorescence autophagy flux assays were carried out. Dual fluorescence spot quantitative analysis was performed by ImageJ (v1.8). Flowcyto clustering was applied by FLOWJO 10. Error bar $=$ mean \pm SD of at least triplicate experiments. $\left({ }^{*} P<0.005\right.$, ${ }^{* * P}<0.01$, $\left.{ }^{* * *} P<0.001,{ }^{* * * *} P<0.0001\right)$

Aloin inhibits osteosarcoma in a mouse xenograft model of osteosarcoma

In the Balb/c nude mouse xenograft model of
MG63

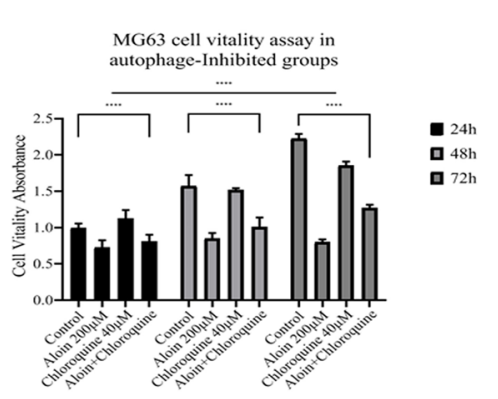

Apoptosis Flowcyto assay in autophage inhibited groups

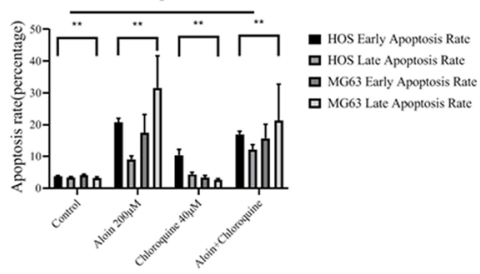

EGFP Control
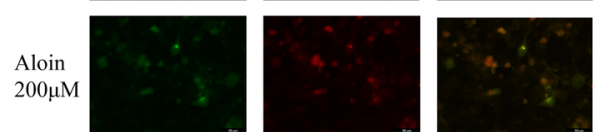

Chloro

quine

$40 \mu \mathrm{M}$
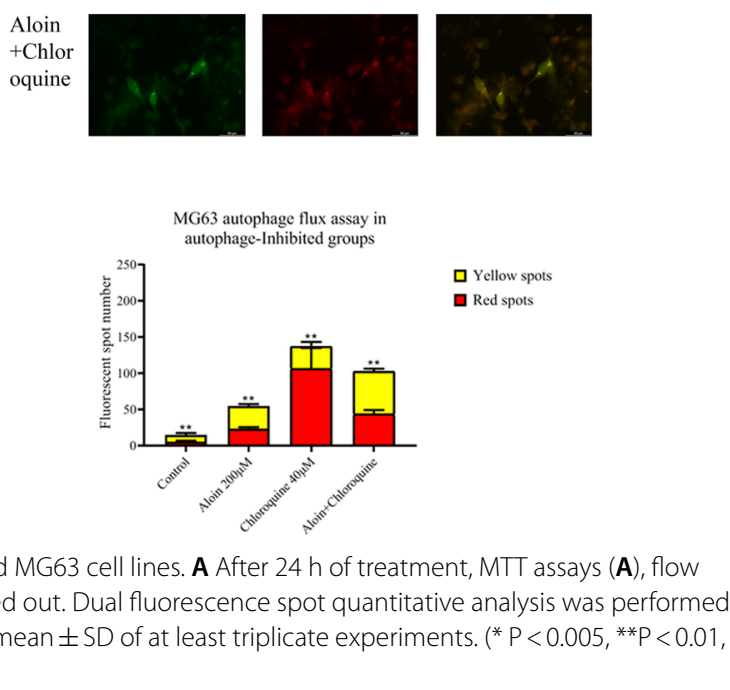

osteosarcoma, aloin obviously inhibited human osteosarcoma cell (HOS) growth. Compared with the control group, the gross tumor volume in the aloin group was 

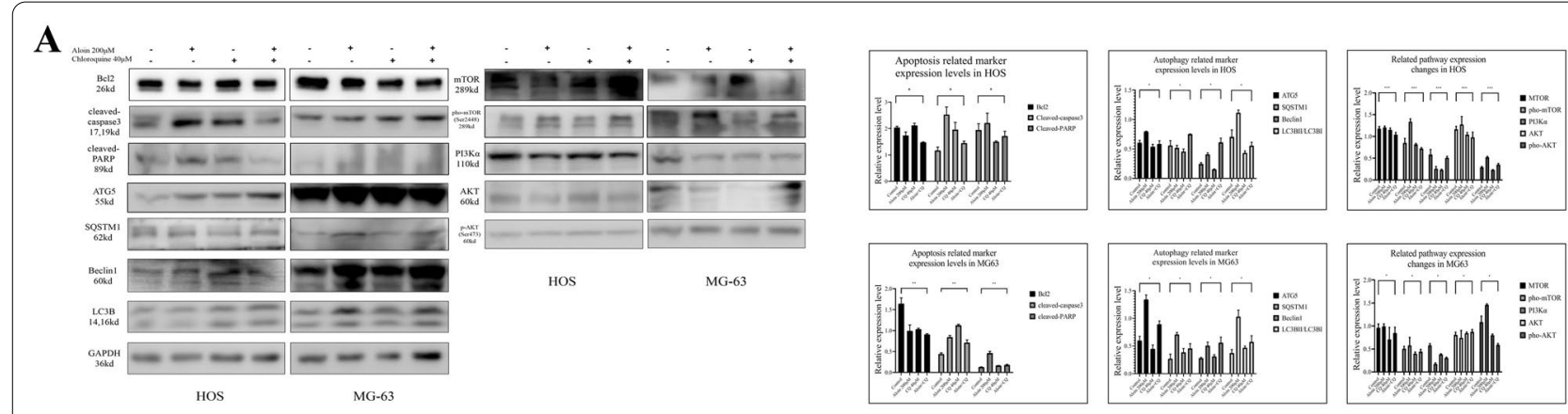

B
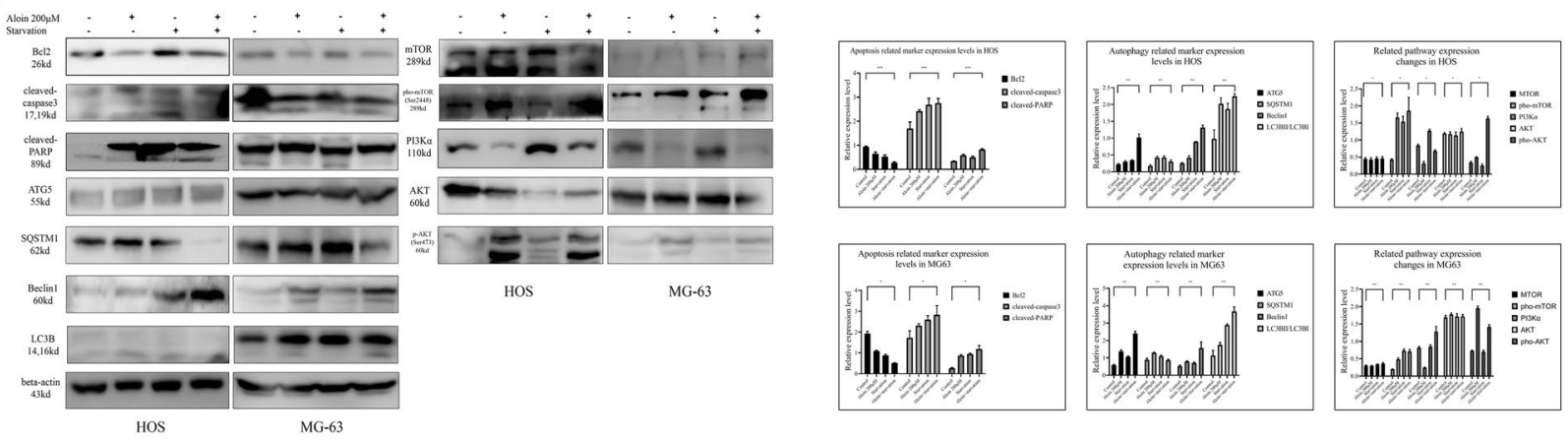

C
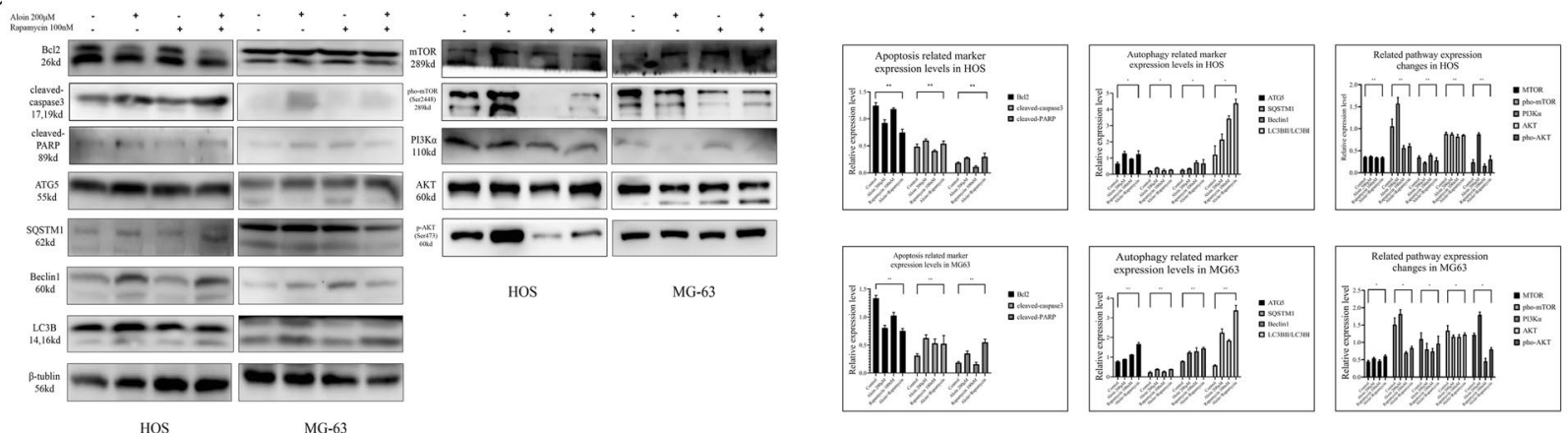

Fig. 7 Protein expression levels in the aloin-chloroquine $(\mathbf{A})$, aloin-starvation (B), and aloin-rapamycin $(\mathbf{C})$ treatment groups. Apoptosis-related protein markers, autophagy-related proteins and PI3K/AKT/mTOR axis protein expression were tested by western blot. Western blot quantitative analysis was performed by ImageJ ( $v 1.8)$. Error bar $=$ mean $\pm S D$ of at least triplicate experiments. $\left({ }^{*} P<0.005,{ }^{* *} P<0.01,{ }^{* * *} P<0.001,{ }^{* * * * P}<0.0001\right)$

smaller. Compared with the cisplatin group, the gross tumor volume in the aloin group was slightly larger (Fig. 10B, C). The IVIS assay showed that the average fluorescence intensity of the control group was the highest. The luminescence intensity of the cisplatin group was significantly lower than that of the control group 7 days after administration. The difference in luminescence intensity was obvious at the end of the 4-week experiment. The luminous intensity of the aloin group was significantly lower than that of the control group after 7 days of administration, but the degree of reduction was less than that of the cisplatin group. At the end of the 4-week experiment, the luminescence intensity of the aloin group was significantly lower than that of the control group, but the overall decrease was still less than that of the cisplatin group. HE staining showed that the cisplatin group shared the highest proportion of necrotic tumor cells. The proportion of necrotic tumor cells in the aloin group was slightly lower than that in the cisplatin group but was significantly higher than that in the control group (Fig. 10A).

Further immunohistochemical analysis confirmed that LC3B, phosphorylated AKT and phosphorylated mTOR expression induced by aloin was increased, while PI3K $\alpha$ expression decreased to a certain extent (Fig. 11A and 
A

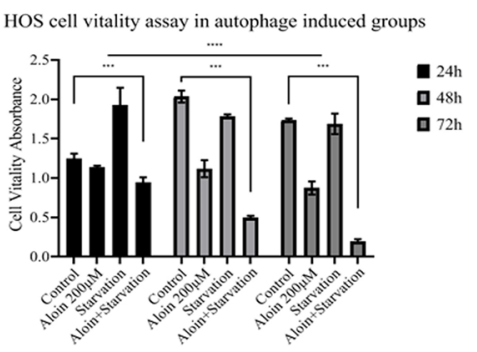

B
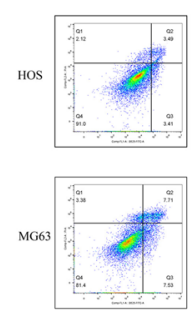

Control
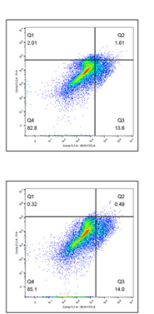

Aloin 200 $\mathrm{M}$
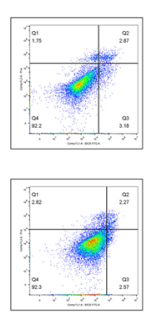

Starvation
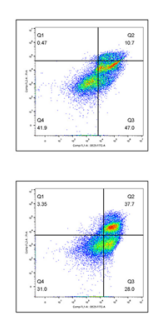

Aloin+Starvation

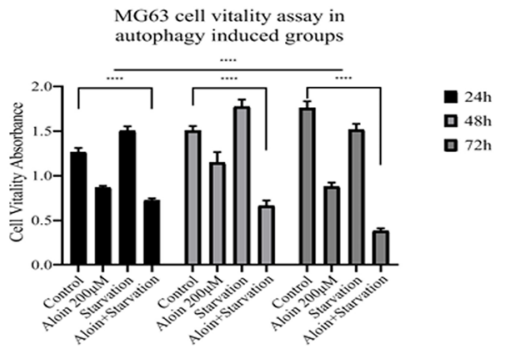

Apoptosis Flowcyto assay in autophage induced groups

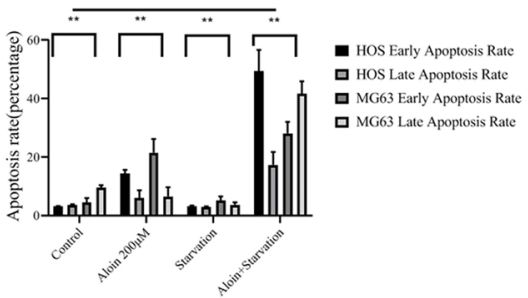

C
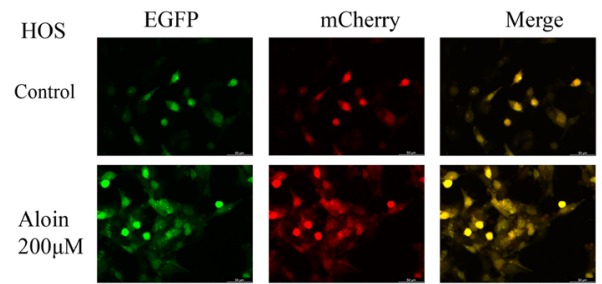

$200 \mu \mathrm{M}$
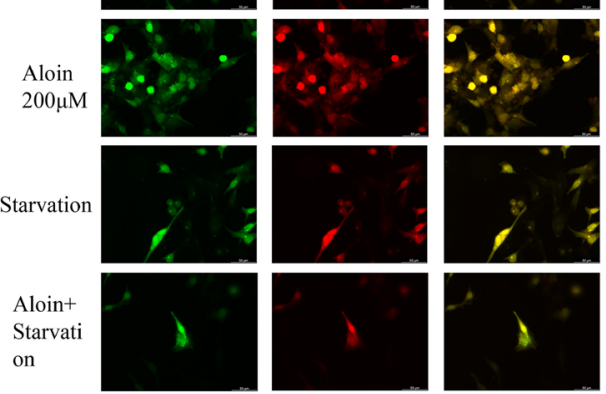

HOS autophage flux assay in

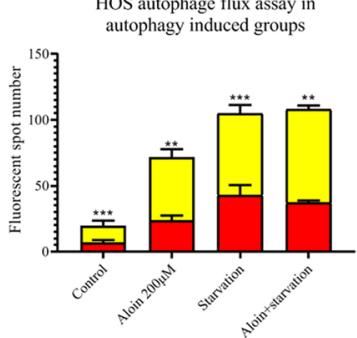

$\square$ Yellow spots

口 Red spots
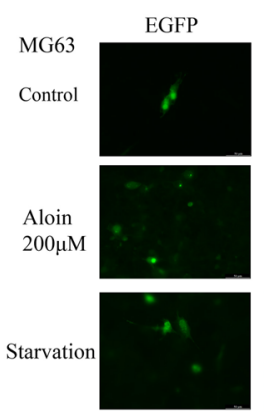

Aloin

+stary ation
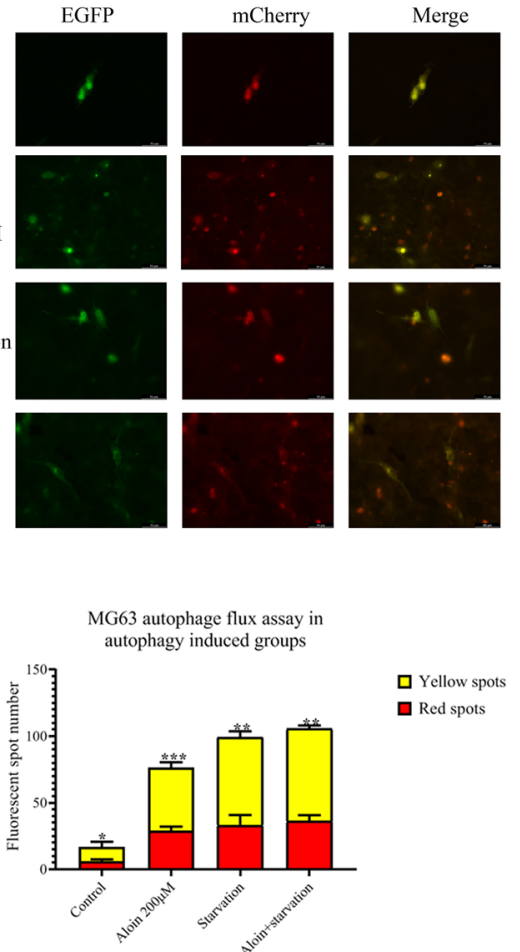

Fig. 8 Aloin and rapamycin coadministration for the mTOR inhibition test in HOS and MG63 cell lines. After 24 h of treatment, MTT assays (A), flow cytometry assays (B), and dual fluorescence autophagy flux assays were carried out. Dual fluorescence spot quantitative analysis was performed by Image ( $\mathrm{v} 1.8)$. Flowcyto clustering was applied by FLOWJO 10. Error bar $=$ mean $\pm \mathrm{SD}$ of at least triplicate experiments. ${ }^{*} \mathrm{P}<0.005$, ${ }^{* *} \mathrm{P}<0.01$, $* * * P<0.001, * * * P<0.0001)$

C). As a commonly used chemotherapeutic drug, cisplatin also causes a certain degree of autophagy in tumor cells. Therefore, LC3B expression in the cisplatin group also increased. Phosphorylated AKT and phosphorylated
mTOR expression in the cisplatin group rose to a certain level. However, the increase in the LC3B amplitude in the cisplatin group was lower than that in the aloin group (Fig. 11A and C). These results indicate that aloin 
A

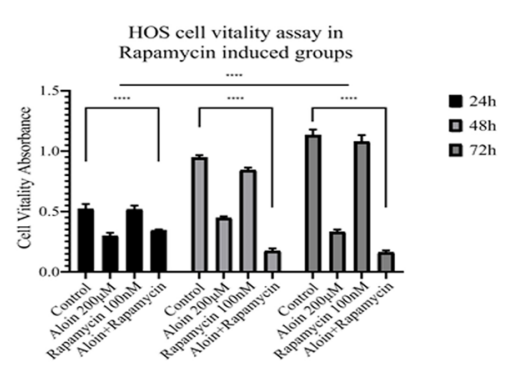

B
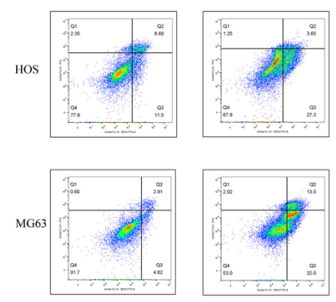

Control

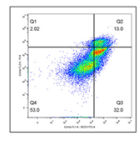

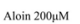
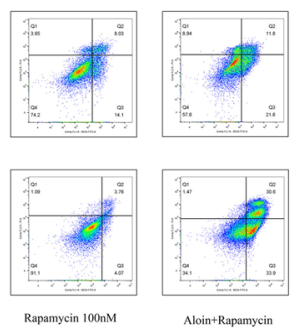

C
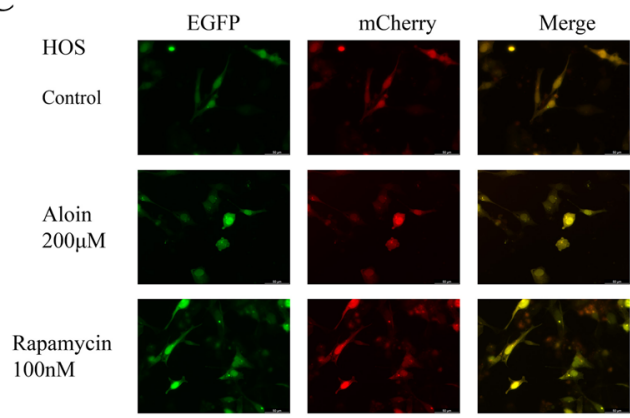

Aloin+

Rapamycin
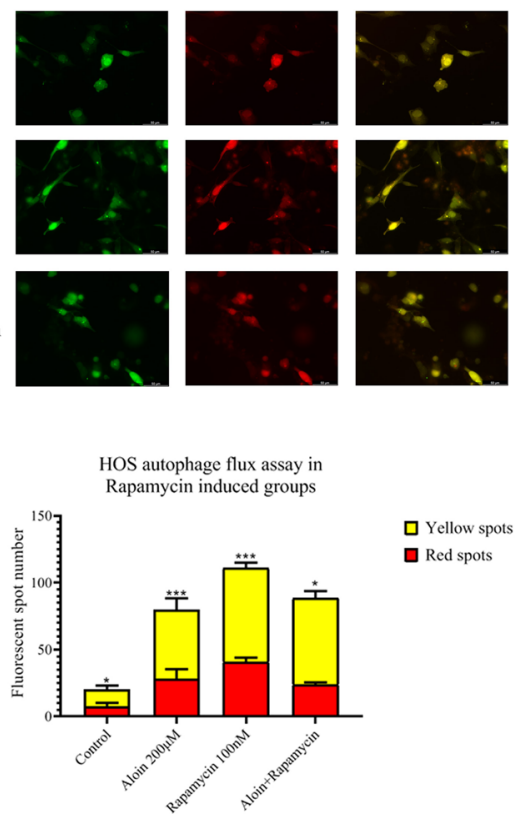

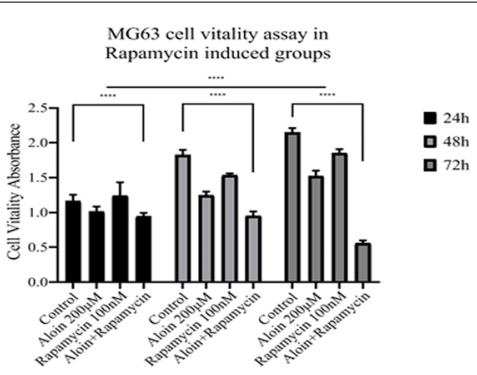

Apoptosis Flowcyto assay in

Rapamycin induced groups
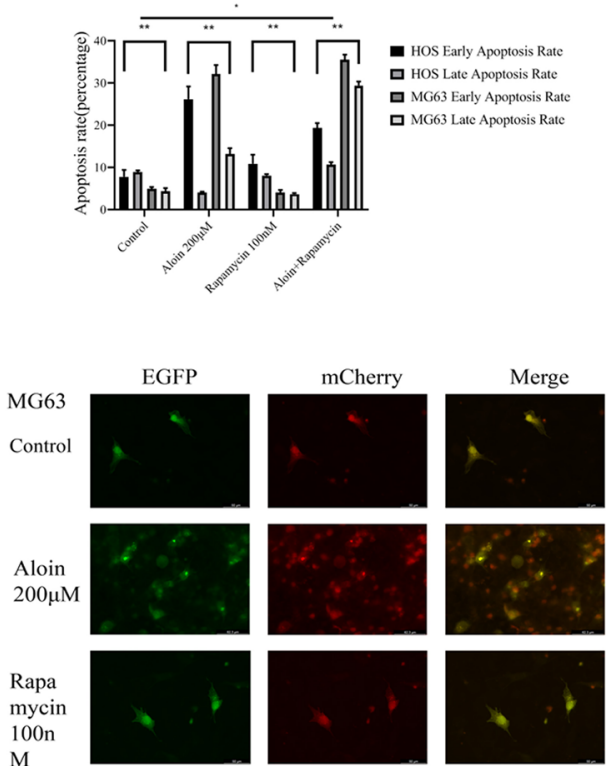

Aloin

Aloin
+ Rapa

mycin
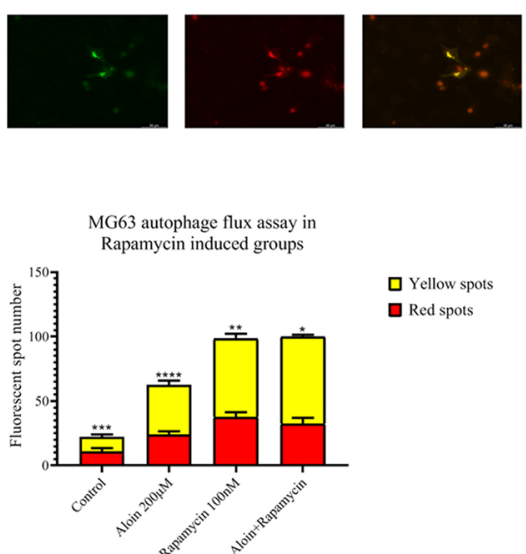

Fig. 9 Aloin and starvation coadministration for the autophagy synergetic assay in HOS and MG63 cell lines. After $24 \mathrm{~h}$ of treatment, MTT assays (A), flow cytometry assays (B), and dual fluorescence autophagy flux assays were carried out. Dual fluorescence spot quantitative analysis was performed by ImageJ (v1.8). Flowcyto clustering was applied by FLOWJO 10. Error bar $=$ mean \pm SD of at least triplicate experiments. $\left({ }^{*} P<0.005\right.$, $\left.{ }^{* *} P<0.01,{ }^{* * *} P<0.001,{ }^{* * * P}<0.0001\right)$

inhibited the growth of tumor cells in osteosarcoma xenograft tumor models and induced autophagy in vivo. Its regulatory effect on the PI3K/AKT/mTOR pathway was also in line with the test results in the in vitro cell culture system. 


\section{A}
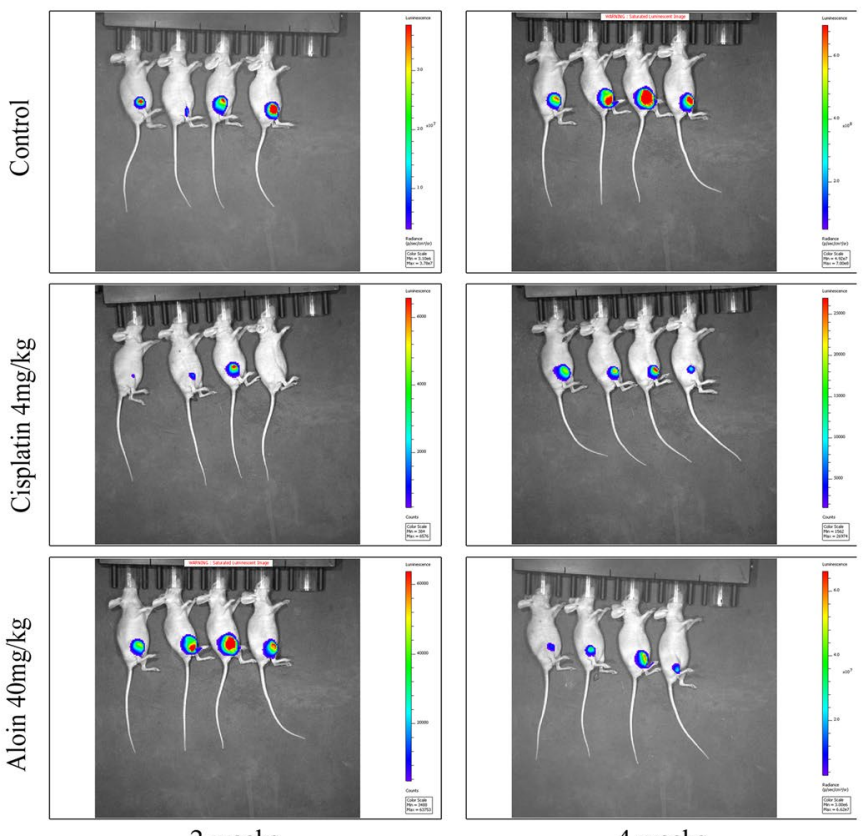

B

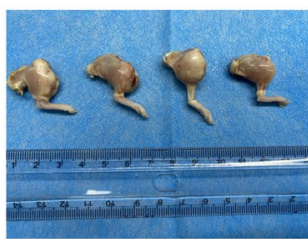

Control

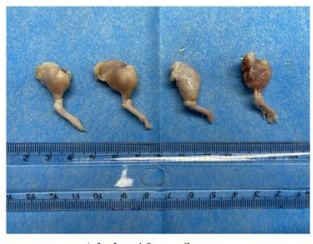

Aloin $40 \mathrm{mg} / \mathrm{kg}$

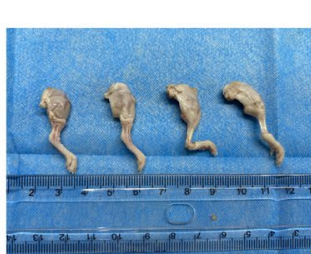

Cisplatin $4 \mathrm{mg} / \mathrm{kg}$

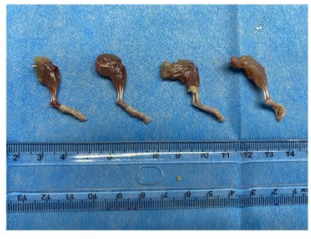

Blank group

C

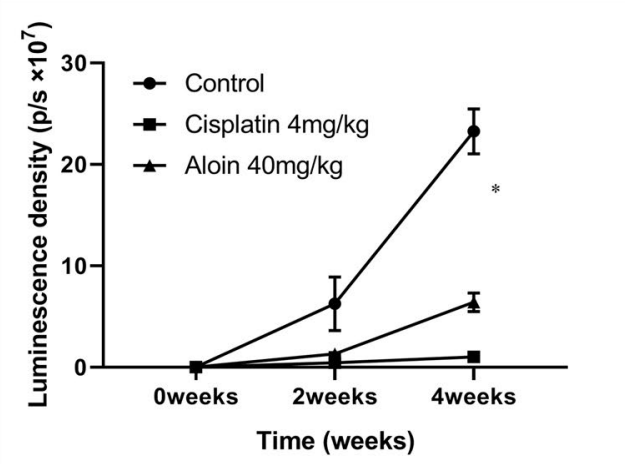

Fig. 10 Aloin inhibited osteosarcoma growth in a xenograft model in BALB/c nude mice. A After 4 weeks of aloin treatment, the luciferase intensity of the tumors was measured at week 2 and week 4. B Gross observation showed significant differences among the control, aloin and cisplatin groups after 4 weeks. C IVIS intensity was measured by Living Image Software (v3.0.4). The cisplatin group was set for comparison, and the blank group was set as the sham-operated group. Error bar $=$ mean \pm SD of at least triplicate experiments. ${ }^{*} P<0.005,{ }^{*} P<0.01,{ }^{* * *} P<0.001$, $* * * * P<0.0001)$

\section{Aloin toxicity test in vivo}

H\&E staining showed that aloin had no obvious toxic effects on the mouse heart, liver, spleen, lungs, or kidneys (Fig. 11B).

\section{Discussion}

Most osteosarcomas originate from primitive mesenchymal cells, which are spindle cells that can differentiate to produce bone tissue. Most of these cells are derived from skeletal tissue, which may transform into malignant tumors $[1,2]$. Osteosarcoma has a higher incidence during adolescence, which results in the annual incidence rate of its adolescent population as high as 8 to 11 cases/ million/year, accounting for $8.9 \%$ of childhood cancerrelated deaths [3]. In addition, a second smaller peak of incidence was found in the elderly [4].

The treatment of primary tumors in osteosarcoma is mainly chemotherapy and surgery [26]. After multidrug 


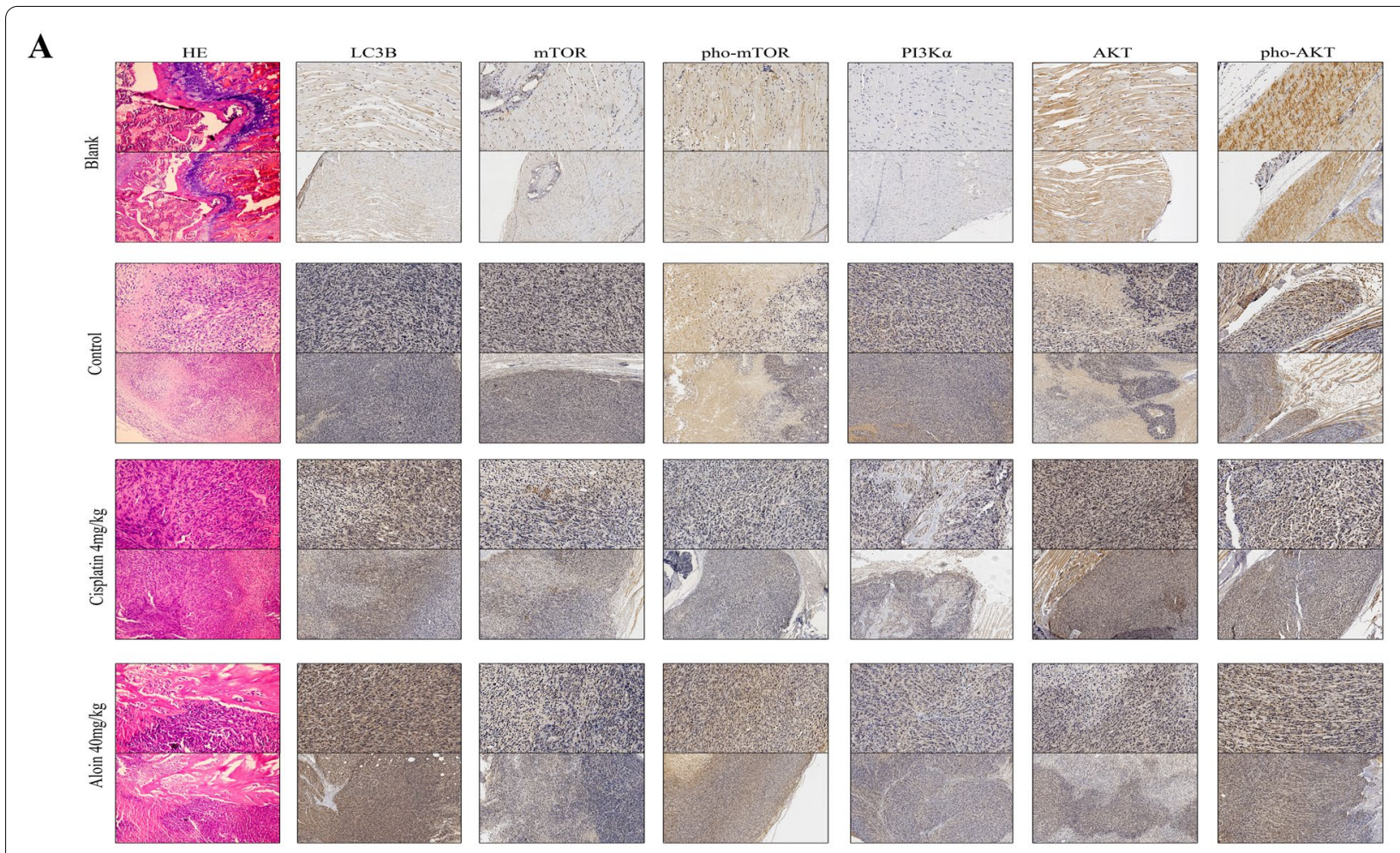

B
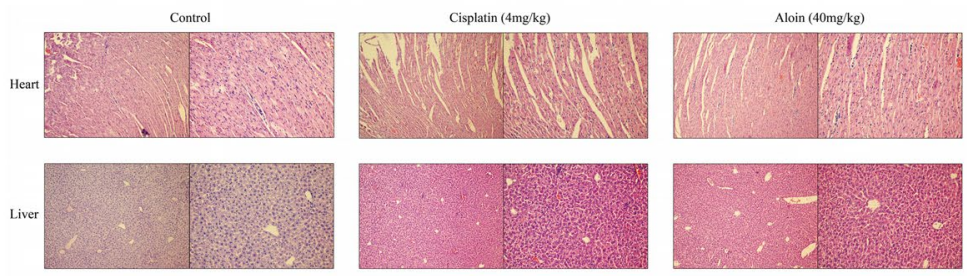

C
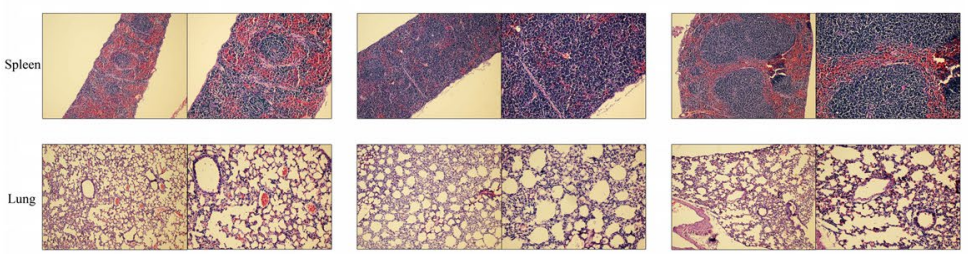

IHC assay in osteosarcoma xenograft model
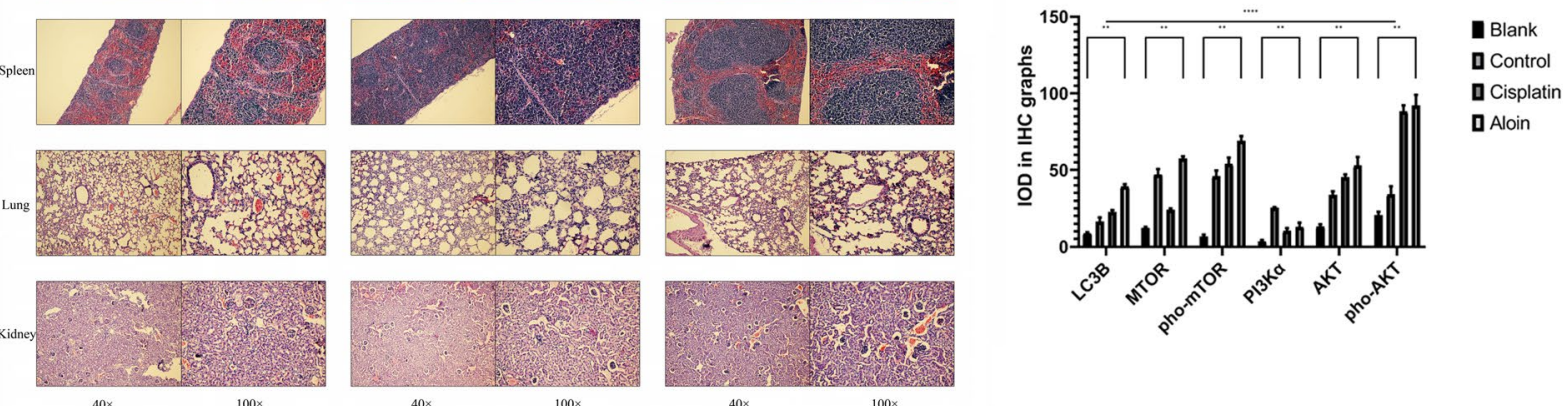

Fig. 11 Histological detection in organs and tumors. A $\| \mathrm{HC}$ and $\mathrm{HE}$ staining were utilized to assess tumor tissue sections. The markers examined were LC3B, mTOR, pho-mTOR, PI3Ka, AKT, and pho-AKT. B Toxic effects on organs were tested by HE staining. C The expression levels of each marker were quantified by ImageJ (v1.8). Magnification, $\times 200$ (enlarged pictures), $\times 40$ (unenlarged pictures). Error bar $=$ mean \pm SD of at least triplicate experiments. $\left({ }^{*} \mathrm{P}<0.005,{ }^{* * P}<0.01,{ }^{* * *} \mathrm{P}<0.001,{ }^{* * * * P}<0.0001\right)$

chemotherapy starts, the long-term survival rate increases to $70 \%[27,28]$. In addition to the therapeutic effect of chemotherapeutics, there were still some problems, such as toxicity to normal tissues, drug resistance and rapid clearance of blood drugs [29].

Aloin inhibited osteosarcoma cell proliferation by inducing apoptosis in a dose- and time-dependent 
manner. Therefore, it was necessary to clarify the mechanism by which aloin inhibited osteosarcoma growth from the perspective of pharmacological properties. We found that as the aloin concentration increased, the total cell number decreased, while the proportion of densely stained cells increased significantly. In this study, the expression levels of activated caspase-3, caspase-7, caspase-9, cleaved PARP, Bcl-2 and Bcl-xl were detected by Western blotting to study the mechanism by which aloin promotes osteosarcoma apoptosis. With increased aloin concentrations, the expression of cleaved-PARP and caspase- 3 , caspase- 7 , and caspase- 9 increased, which induced apoptosis.

Members of the caspase family of proteins interact with autophagy-related proteins [31]. For example, caspase-3 inhibited autophagy by cleaving Beclin-1 to inactivate it. Increased Beclin-1 expression in turn promoted caspase- 9 activity and promoted the occurrence of apoptosis [31, 32]. The mechanism by which aloin promotes apoptosis of osteosarcoma cells may involve the cross link between programmed death of tumor cells and autophagy.

We divided the antitumor target screening strategy of aloin into six steps. 1. Reverse virtual screening of potential targets for drug molecules through the PharmMapper database; 2. Protein interaction analysis; 3 . KEGG pathway enrichment cluster analysis and key network construction: enrichment analysis screens and optimizes important sites involved in autophagy regulation and antitumor-related mechanisms; 4. Forward molecular docking research verification: forward molecular docking analysis potential target binding score; 5 . Verification in in vitro cell culture system; and 6. Validation in animal models. Pharmacophore matching reverse screening of the possible targets of the antitumor effect of aloin was regarded as the starting point for preliminary screening research.

To reduce the probability of false-positive targets, previous studies were based on the Fitscore or Normal Fitscore, according to the purpose and means of the research [40, 41]. Combined with known sites of previous studies, we selected the PI3K/AKT/mTOR axis as a key research checkpoint and verified its pathway changes through experiments such as western blotting.

It was more effective to study interactions between small molecule compounds and signal pathway networks through bioinformatics methods [33]. This research strategy has become a common method for the efficient manufacturing of various inhibitors and activators [34]. This research evidence gave us reason to believe that these protein targets might be the key targets of aloin. Therefore, we extracted AKT, EGFR, CASP3, SRC, MAPK8, and MAPK14 for the next step of molecular docking verification.

Among the 6 target proteins, AKT1 had a considerable match score $(-8.2)$, indicating that aloin was a firm and stable ligand that binds to AKT1. Compared with targets other than AKT1, SRC and EGFR also showed higher matching levels of -8.4 and -8.3 , respectively, while MAPK8 and MAPK14 scored -8.0 , and CASP3 scored -7.6. The PI3K/AKT signaling pathway, which we finally focused on, had important regulatory functions in oxidative stress, autophagy, metabolism, growth, proliferation, survival, transcription and protein synthesis. As important cancer regulatory nodes, EGFR and SRC also cross-talk with the PI3K/ AKT pathway [35]. JNK (MAPK8), an important part of the MAPK signaling pathway, participates in processes such as apoptosis, oxidative stress, autophagy, and inflammation [36]. The PI3K/AKT axis was closely related to the occurrence of autophagy. Therefore, we decided to discuss autophagy as the key node in this study.

Aloin treatment of osteosarcoma cells increased the autophagic flux in a dose-dependent manner. We administered chloroquine (autophagy inhibitor), rapamycin (mTOR inhibitor), and starvation treatment to the culture system for further studies. Chloroquine inhibited aloin-induced apoptosis to a certain degree, while starvation and rapamycin treatment synergistically enhanced aloin's induction of autophagy and apoptosis.

In this study, the formation of autophagosomes and the expression of autophagy markers after aloin treatment of osteosarcoma cells were detected. Upregulation of Beclin-1 and changes in the ratio of LC3I and LC3II were considered signs of increased autophagic flux [37, 38 ]. We found that aloin upregulated Beclin-1, increased LC3I and LC3II expression and promoted the conversion from LC3I to LC3II. Chloroquine reduced aloin-induced apoptosis to a certain extent by inhibiting autophagy. Therefore, the chloroquine turnover test proved that aloin promoted apoptosis of osteosarcoma cells by inducing autophagy.

After chloroquine and aloin were used to cotreat HOS and MG63 cells, apoptosis-related proteins were downregulated in the cotreatment group compared with the separate treatment groups and control group. The trends of autophagy-related proteins ATG5, P62, LC3B, Beclin-1, etc. also reflected that chloroquine inhibited the autophagy enhancement effect of aloin. ATG5 and LC3B exhibited more obvious inhibitory effects, while P62 and Beclin-1 showed slightly lower suppressive effects. After cotreatment with aloin and chloroquine, autophagolysosomes were reduced compared with those of the chloroquine group, while autophagosomes 
increased significantly. This trend was also consistent with the results of changes in autophagy-related protein expression.

Aloin treatment promoted the phosphorylation of AKT and mTOR, indicating the activation of AKT and mTOR. $\mathrm{AKT}$ and mTOR are two classic cancer-promoting pathways and are regarded as downstream sites of PI3K/ AKT/mTOR [39]. The activation of mTOR inhibited autophagy, while mTOR inhibition often enhanced the process of autophagy [39]. Therefore, in follow-up studies, we conducted further studies on the effects of aloin, chloroquine, starvation treatment and rapamycin on the PI3K-AKT-mTOR signaling pathway in osteosarcoma cells.

Starvation treatment was applied to synergize with aloin-promoted autophagy, and rapamycin was used as a mTOR inhibitor to reverse aloin-promoted mTOR phosphorylation. Autophagosomes in the aloin starvation treatment groups were significantly increased. Cell viability was significantly inhibited, and the apoptosis ratio was significantly increased. Western blot detection also showed that the expression of apoptosis-related markers and autophagy-related proteins increased significantly. The PI3K/AKT/mTOR axis was further inhibited to a certain extent, in which PI3K $\alpha$ was inhibited.

When rapamycin was used as a mTOR inhibitor, aloinpromoted AKT and mTOR phosphorylation was inhibited by rapamycin, while PI3K $\alpha$ inhibition induced by aloin was not relieved. In the rapamycin alone group, rapamycin-blocked mTOR returned to the expression of PI3K $\alpha$ to promote its upregulation. However, this effect did not reverse aloin-induced PI3K $\alpha$ inhibition in the combination group. The final biological effect of the combination of aloin and rapamycin was still the upregulation of autophagy and inhibition of osteosarcoma cells. In contrast, the synergy of aloin and rapamycin resulted in a stronger apoptosis effect and autophagy flux induction. Therefore, we believe that aloin has a higher regulatory priority on PI3K. The upregulation of AKT and mTOR phosphorylation might be a feedback effect during the regulation process or crosstalk that needs further interaction study.

The results of animal model experiments showed that aloin significantly inhibited the growth rate of osteosarcoma after 4 weeks of administration, and its therapeutic effect was slightly inferior to that of the cisplatin chemotherapy group. The autophagy marker LC3B was significantly upregulated, indicating that aloin induced autophagic flux in osteosarcoma cells in vivo. In the aloin group, the expression level of PI3K $\alpha$ was significantly downregulated, while phosphorylated mTOR and phosphorylated AKT levels were significantly increased. This indicated that aloin induced autophagy and apoptosis of osteosarcoma through the PI3K/AKT/mTOR pathway in vivo. HE staining microscopic examination of vital organs also found no significant pathological changes in the aloin group.

\section{Conclusion}

Aloin dose-dependently inhibited osteosarcoma proliferation and increased the autophagic flux. Network pharmacology and bioinformatics research inferred that aloin may inhibit osteosarcoma through the PI3K/AKT/mTOR pathway. Subsequent studies verified that aloin mediated the autophagic flux increase and osteosarcoma apoptosis through the PI3K/AKT/mTOR axis. As an inhibitor of autophagy, chloroquine reversed the autophagic flux increase with aloin. Meanwhile, starvation and rapamycin cooperated with the autophagy-inducing function of aloin. An osteosarcoma xenograft model showed that aloin inhibited osteosarcoma and mediated the PI3K/ $\mathrm{AKT} / \mathrm{mTOR}$ pathway in vivo, with no adverse reactions in major organs. We may infer that aloin may have the potential as an adjuvant drug for chemotherapy in osteosarcoma treatment.

\begin{abstract}
Abbreviations
AKT: Protein kinase B; ATG: Autophagy related gene; DMEM: Dulbecco's modified Eagle's medium; DMSO: Dimethylsulfoxide; EGFR: Epidermal Growth Factor Receptor; FACS: Fluorescence Activating Cell Sorter; FITC: Fluorescein Isothiocyanate; HE: Hematoxylin-eosin; HRP: Horseradish Peroxidase; IHC: Immunohistochemistry; IVIS: In vivo Bioluminescence imaging system; KEGG: Kyoto Encyclopedia of Genes and Genomes; MAPK: Mitogenactivated protein kinase; mTOR: Mammalian target of rapamycin; MTT: 3-(4,5)-Dimethylthiahiazo(-2)-3,5-diphenytetrazoliumromide; PARP: Poly ADPribose polymerase; PBS: Phosphate buffered saline; PI: Propidium lodide; PI3K: Phosphatidylinositol 3 kinase; PPI: Protein-protein interaction; SD: Standard Deviation; SQSTM: Sequestosome; UCSF: University of California, San Francisco.
\end{abstract}

\section{Supplementary Information}

The online version contains supplementary material available at https://doi. org/10.1186/s13020-021-00520-4.

Additional file 1. Data declaration

Additional file 2

Additional file 3

\section{Acknowledgements}

Gratitude should be expressed to the colleagues of Key Laboratory of Motor System Disease Research and Precision Therapy of Zhejiang Province, clinical research center and animal laboratory of the Second Affiliated Hospital Zhejiang University School of Medicine for giving precious help in this research.

\section{Authors' contributions}

ZW contributed to the conception of the study. JMH conceived, designed the experiments and performed the majority of experiments. WKZ performed animal model experiments of this research. XZZ contributed analysis of the data. WQY conducted supervision and essential guidance. 


\section{Funding}

This work was supported by China Postdoctoral Science Foundation (2021M692792) and was granted from the National Natural Science Foundation of China (No. 81772325, No.82103499).

\section{Availability of data and materials}

The datasets generated and/or analysed during the current study are available in the Mendeley repository, https://data.mendeley.com/datasets/wn45tscc28/ draft?a=b4172ac4-f662-49b6-9ec3-cc88bd13de23 (Further inquiries can be directed to the corresponding authors).

\section{Declarations}

\section{Ethics approval and consent to participate}

All experiments were carried out in accordance with the guidelines of the Ethics Committee of Zhejiang University and approved by the Research Ethics Committee of the Second Affiliated Hospital of Zhejiang University School of Medicine, China.

\section{Consent for publication}

Not applicable.

\section{Competing interests}

The authors declare that they have no competing interests.

\section{Author details}

${ }^{1}$ Department of Orthopedic Surgery, The Second Affiliated Hospital, Zhejiang University School of Medicine, Hangzhou, China. ${ }^{2}$ The Second Affiliated Hospital, Zhejiang University School of Medicine, Hangzhou, China. ${ }^{3}$ Key Laboratory of Motor System Disease Research and Precision Therapy of Zhejiang Province, Hangzhou, China.

\section{Received: 24 August 2021 Accepted: 12 October 2021}

Published online: 24 November 2021

\section{References}

1. Picci P, Mercuri M, Ferrari S, Alberghini M, Briccoli A, Ferrari C, Pignotti E, Bacci G. Survival in high-grade osteosarcoma: improvement over 21 years at a single institution. Ann Oncol. 2010;21(6):1366-73. https://doi.org/10. 1093/annonc/mdp502.

2. Isakoff MS, Bielack SS, Paul M, Richard G. Osteosarcoma: current treatment and a collaborative pathway to success. J Clin Oncol. 2015;33(27):3029_ 35. https://doi.org/10.1200/JCO.2014.59.4895.

3. Giulia O, Norman J. The epidemiology of osteosarcoma. Cancer Treat Res. 2009;152:3-13. https://doi.org/10.1007/978-1-4419-0284-9_1.

4. Bielack SS, Hecker-Nolting S, Blattmann C, Kager L. Advances in the management of osteosarcoma. F1000Res. 2016;5:2767. https://doi.org/ 10.12688/f1000research.9465.1.

5. Zhifen Y, Klionsky DJ. An overview of the molecular mechanism of autophagy. Curr Top Microbiol Immunol. 2009;335:1-32. https://doi.org/ 10.1007/978-3-642-00302-8_1.

6. Lalaoui N, Lindqvist LM, Sandow JJ, Ekert PG. The molecular relationships between apoptosis, autophagy and necroptosis. Semin Cell Dev Biol. 2015;39:63-9. https://doi.org/10.1016/j.semcdb.2015.02.003.

7. Xinbing S, Lijun J, Xuefeng H, Shumin G, Chao He, Xiaotong Hu. p53 signaling and autophagy in cancer: a revolutionary strategy could be developed for cancer treatment. Autophagy. 2011;7(6):565-71. https:// doi.org/10.4161/auto.7.6.14073.

8. Kundu M, Thompson CB. Autophagy: basic principles and relevance to disease. Annu Rev Pathol. 2008;3:427-55. https://doi.org/10.1146/annur ev.pathmechdis.2.010506.091842.

9. Saraf AJ, Fenger JM, Roberts RD. Osteosarcoma: accelerating progress makes for a hopeful future. Front Oncol. 2018;8:4. https://doi.org/10.3389/ fonc.2018.00004.

10. Jordi R, Rodrigo D, Violeta S, Josep T. Development of PI3K inhibitors: lessons learned from early clinical trials. Nat Rev Clin Oncol. 2013;10(3):14353. https://doi.org/10.1038/nrclinonc.2013.10.
11. Eisuke I, Noboru M. Characterization of autophagosome formation site by a hierarchical analysis of mammalian Atg proteins. Autophagy. 2010;6(6):764-76. https://doi.org/10.4161/auto.6.6.12709.

12. Russell RC, Hai-Xin Y, Kun-Liang G. Autophagy regulation by nutrient signaling. Cell Res. 2014;24(1):42-57. https://doi.org/10.1038/cr.2013.166.

13. Wang $Y$, Zhang $H$. Regulation of autophagy by mTOR signaling pathway. Adv Exp Med Biol. 2019;1206:67-83. https://doi.org/10.1007/ 978-981-15-0602-4_3.

14. Shi-Yong S. Enhancing perifosine's anticancer efficacy by preventing autophagy. Autophagy. 2010;6(1):184-5. https://doi.org/10.4161/auto.6.1. 10816.

15. Joungmok K, Mondira K, Benoit $V$, Kun-Liang G. AMPK and mTOR regulate autophagy through direct phosphorylation of Ulk1. Nat Cell Biol. 2011;13(2):132-41. https://doi.org/10.1038/ncb2152.

16. Mandell MA, Ashish J, John A-M, Santosh C, Tomonori K, Christina D, Guido S, Jan M, Frank K, Anne S, Yongjie W, Beth L, Terje J, Vojo D. TRIM proteins regulate autophagy and can target autophagic substrates by direct recognition. Dev Cell. 2014;30(4):394-409. https://doi.org/10. 1016/j.devcel.2014.06.013.

17. Yoshiaki K, Ken-ichi Y, Chika K, Tomoko K, Noriko O, Kazuyoshi Y, Yoshinori O. Tor directly controls the Atg1 kinase complex to regulate autophagy. Mol Cell Biol. 2010;30(4):1049-58. https://doi.org/10.1128/MCB.01344-09.

18. Sánchez M, González-Burgos E, Iglesias I, Gómez-Serranillos MP. Aloe verapharmacological update properties of and its major active constituents. Molecules. 2020. https://doi.org/10.3390/molecules25061324.

19. Esmat AY, Catherine T, Marie-Christine R. Cytotoxicity of a natural anthraquinone (Aloin) against human breast cancer cell lines with and without ErbB-2: topoisomerase Ilalpha coamplification. Cancer Biol Ther. 2006;5(1):97-103. https://doi.org/10.4161/cbt.5.1.2347.

20. Esmat AY, El-Gerzawy SM, Amira R. DNA ploidy and S phase fraction of breast and ovarian tumor cells treated with a natural anthracycline analog (aloin). Cancer Biol Ther. 2005;4(1):108-12. https://doi.org/10. 4161/cbt.4.1.1445.

21. Nićiforović A, Adzić M, Spasić SD, Radojcić MB. Antitumor effects of a natural anthracycline analog (Aloin) involve altered activity of antioxidant enzymes in HeLaS3 cells. Cancer Biol Ther. 2007;6(8):1200-5. https://doi. org/10.4161/cbt.6.8.4383

22. Claudio T, Stefania R, Alessandro L, Bruno P, Lorenzo T, Francesco F, Simone B. Aloin enhances cisplatin antineoplastic activity in B16-F10 melanoma cells by transglutaminase-induced differentiation. Amino Acids. 2013;44(1):293-300. https://doi.org/10.1007/s00726-011-1166-x.

23. Buenz EJ. Aloin induces apoptosis in Jurkat cells. Toxicol In Vitro. 2008;22(2):422-9. https://doi.org/10.1016/j.tiv.2007.10.013.

24. Nora H, Löffler AS, Takeshi K, Niklas B, Philip B, Stefan D, Fabian S, Olena F, Kaivon A, Katharina S, Christoph P, Britta D, Jörn D, Petter H, Anne S, Sebastian W, Noboru M, Björn S. Expression of a ULK1/2 binding-deficient ATG13 variant can partially restore autophagic activity in ATG13-deficient cells. Autophagy. 2015;11(9):1471-83. https://doi.org/10.1080/15548627. 2015.1068488.

25. Lindsey BA, Markel JE, Kleinerman ES. Osteosarcoma overview. Rheumatol Ther. 2017:4(1):25-43. https://doi.org/10.1007/s40744-016-0050-2.

26. Miwa S, Shirai T, Yamamoto N, Hayashi K, Takeuchi A, Igarashi K, Tsuchiya H. Current and emerging targets in immunotherapy for osteosarcoma. J Oncol. 2019;2019:7035045. https://doi.org/10.1155/2019/7035045.

27. Wang Z, Wang Z, Li B, Wang S, Chen T, Ye Z. Innate immune cells: a potential and promising cell population for treating osteosarcoma. Front Immunol. 2019;10:1114. https://doi.org/10.3389/fimmu.2019.01114.

28. Arndt CA, Crist WM. Common musculoskeletal tumors of childhood and adolescence. N Engl J Med. 1999;341(5):342-52. https://doi.org/10.1056/ NEJM199907293410507.

29. Shang-Yu W, Hong-Zhi Hu, Xiang-Cheng Q, Zhi-Cai Z, Zeng-Wu S. Recent advances of drug delivery nanocarriers in osteosarcoma treatment. J Cancer. 2020;11(1):69-82. https://doi.org/10.7150/jca.36588.

30. Guillermo M, Mireia N-S, Baehrecke EH, Guido K. Self-consumption: the interplay of autophagy and apoptosis. Nat Rev Mol Cell Biol. 2014;15(2):81-94. https://doi.org/10.1038/nrm3735.

31. Lei-lei Fu, Yan C, Bo L. Beclin-1: autophagic regulator and therapeutic target in cancer. Int J Biochem Cell Biol. 2013;45(5):921-4. https://doi.org/ 10.1016/j.biocel.2013.02.007.

32. Daisuke F, Naoki T, Atsuhito Y, Naoki W. Beclin 1 augmented cis-diamminedichloroplatinum induced apoptosis via enhancing caspase-9 
activity. Exp Cell Res. 2005;307(1):26-40. https://doi.org/10.1016/j.yexcr. 2005.02.023.

33. Maozi C, Yankang J, Lirong W, Zhiwei F, Xiang-Qun X. DAKB-GPCRs: an integrated computational platform for drug abuse related GPCRs. J Chem Inf Model. 2019;59(4):1283-9. https://doi.org/10.1021/acs.jcim.8b00623.

34. Ioanna P, Sam L, Claude L, Jan T, Karolien DB. Modulation of proteinprotein interactions for the development of novel therapeutics. Mol Ther. 2016;24(4):707-18. https://doi.org/10.1038/mt.2015.214.

35. Garcia-Lezana T, Lopez-Canovas JL, Villanueva A. Signaling pathways in hepatocellular carcinoma. Adv Cancer Res. 2021;149:63-101. https://doi. org/10.1016/bs.acr.2020.10.002.

36. Qinghua Wu, Wenda Wu, Bishi Fu, Lei S, Wang Xu, Kamil K. JNK signaling in cancer cell survival. Med Res Rev. 2019;39(6):2082-104. https://doi.org/ $10.1002 /$ med.21574.

37. Mihwa K, Ji-Yeon J, Seungho C, Hyunseung L, Morales LD, Jeong-Tae K, Hun KS, Yoo-Duk C, Chan C, Slaga TJ, Jae KW, Joon KD. GFRA1 promotes cisplatin-induced chemoresistance in osteosarcoma by inducing autophagy. Autophagy. 2017;13(1):149-68. https://doi.org/10.1080/15548 627.2016.1239676.

38. Zhuo Y, Fuhua X, Min Li, Zirui L, Wenli Xu, Jianhua Y, Chang L, Hongwangwang Li, Hui Z, Liang-Hu Qu. Oridonin induces autophagy via inhibition of glucose metabolism in p53-mutated colorectal cancer cells. Cell Death Dis. 2017;8(2): e2633. https://doi.org/10.1038/cddis.2017.35.

39. Shanware NP, Bray K, Abraham RT. The PI3K, metabolic, and autophagy networks: interactive partners in cellular health and disease. Annu Rev Pharmacol Toxicol. 2013;53:89-106. https://doi.org/10.1146/annurevpharmtox-010611-134717.

40. Boudreau MD, Olson GR, Tryndyak VP, Bryant MS, Felton RP, Beland FA. From the cover: aloin, a component of the aloe vera plant leaf, induces pathological changes and modulates the composition of microbiota in the large intestines of F344/N male rats. Toxicol Sci. 2017;158(2):302-18. https://doi.org/10.1093/toxsci/kfx105.

41. Hao S, Yiting S, Guangwen L, Yuepiao C, Zheng X. An integrated strategy for identifying new targets and inferring the mechanism of action: taking rhein as an example. BMC Bioinformatics. 2018;19(1):315. https://doi.org/ 10.1186/s12859-018-2346-4.

42. Xia W, Chenxu P, Jiayu G, Xiaofeng L, Honglin Li. Enhancing the enrichment of pharmacophore-based target prediction for the polypharmacological profiles of drugs. J Chem Inf Model. 2016;56(6):1175-83. https:// doi.org/10.1021/acs.jcim.5b00690.

43. Wang X, Shen Y, Wang S, Li S, Zhang W, Liu X, Lai L, Pei J, Li H. PharmMapper 2017 update: a web server for potential drug target identification with a comprehensive target pharmacophore database. Nucleic Acids Res. 2017:45:W356-60. https://doi.org/10.1093/nar/gk×374.

44. Liu X, Ouyang S, Yu B, Liu Y, Huang K, Gong J, Zheng S, Li Z, Li H, Jiang H. PharmMapper server: a web server for potential drug target identification using pharmacophore mapping approach. Nucleic Acids Res. 2010;38:W609-14. https://doi.org/10.1093/nar/gkq300.

45. Pettersen EF, Goddard TD, Huang CC, Couch GS, Greenblatt DM, Meng EC, Ferrin TE. UCSF Chimera-a visualization system for exploratory research and analysis. J Comput Chem. 2004;25(13):1605-12. https://doi.org/10. $1002 / j c c .20084$

\section{Publisher's Note}

Springer Nature remains neutral with regard to jurisdictional claims in published maps and institutional affiliations.
Ready to submit your research? Choose BMC and benefit from:

- fast, convenient online submission

- thorough peer review by experienced researchers in your field

- rapid publication on acceptance

- support for research data, including large and complex data types

- gold Open Access which fosters wider collaboration and increased citations

- maximum visibility for your research: over 100M website views per year

At BMC, research is always in progress.

Learn more biomedcentral.com/submissions 